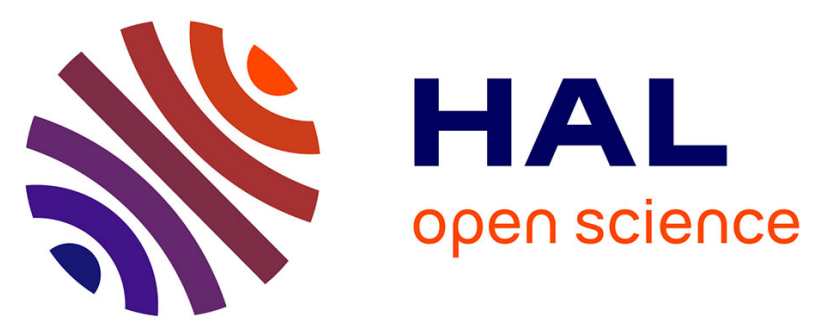

\title{
La formation des enfants d'agriculteurs et leur orientation d'emploi : études complémentaires à une enquête statistique en Ille-et-Vilaine
}

Pierre Daucé, Guenhaël Jegouzo, Yves Lambert, Bernard Roze

\section{To cite this version:}

Pierre Daucé, Guenhaël Jegouzo, Yves Lambert, Bernard Roze. La formation des enfants d'agriculteurs et leur orientation d'emploi: études complémentaires à une enquête statistique en Ille-et-Vilaine. [Rapport de recherche] Station d'Économie et Sociologie rurales. 1971, 47-23 p. hal02403492

\section{HAL Id: hal-02403492 \\ https://hal.science/hal-02403492}

Submitted on 10 Dec 2019

HAL is a multi-disciplinary open access archive for the deposit and dissemination of scientific research documents, whether they are published or not. The documents may come from teaching and research institutions in France or abroad, or from public or private research centers.
L'archive ouverte pluridisciplinaire HAL, est destinée au dépôt et à la diffusion de documents scientifiques de niveau recherche, publiés ou non, émanant des établissements d'enseignement et de recherche français ou étrangers, des laboratoires publics ou privés.

\section{(ㅇ)(1) $\$$}

Distributed under a Creative Commons Attribution - NonCommercial - NoDerivatives 44.0 
INSTITUT NATIONAL DE LA RECHERCHE AgRONOMIQUE Station diEconomie Rurale de Rennes

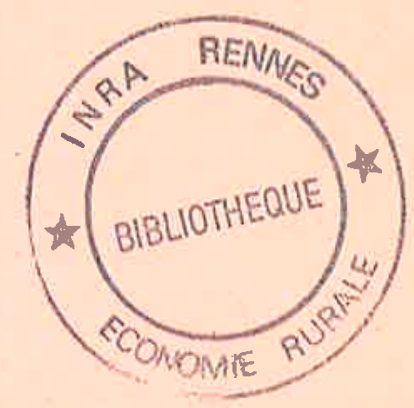

LA FORMATION DES ENFANTS D'AGRICULTEURS ET LEUR ORIENTATION DIEMPLOI:

ETUDES COMPLEMENTAIRES A UNE ENQUETE STATISTIQUE EN ILLE-ET-VILAINE

P. DAUCE, G. JEGOUZO et Y. LAMBERT avec la collaboration de $B$. ROZE 



\section{AVERTISSEMENT}

Une enquête statistique a été faite en 1970 dans le département d'llle-et-Vilaine pour étudier la formation reçue et les emplois exercés par des enfants d'agricul teurs nés de 1945 à 1955 . Il en a été rendu comp te dans un précédent document : "La formation des enfants d'agriculteurs et leur orientation hors de l'agriculture; résultats d'une enquête exploratoire en llle-et-Vilaine", I. N.R.A. - Station d'Economie Rurale de Pennes, janvier 1971.

Cette étude, effectuée auprès des familles, a fait apparaître que des diverses catégories d'éducation clest la formation agricole courte qui retient le plus dans l'agriculture, mais le petit nombre de cas ne permet pas de conclure en ce qui concerne la formation agricole longue. D'autre part, parmi les enfants d!agriculteurs qui slorientent vers les emplois non agricoles, nombreux sont ceux qui se présentent sur le marché du travail sans avoir de qualification.

Deux autres études, réal isées également en llle-et-Vilaine, ont permis en particulier d'approfondir ces deux points :

1 - Des élèves en cours de scolarité dans une institution composée dlun collège général et d'un établissement agricole ont été interrogés sur leur passé scolaire et leurs projets professionnels. L'orientation d'emploi des élèves du collège agricole a été analysée en distinguant cycle court et cycle long et par comparaison avec celle des élèves du collège général. Cette étude d'ordre monographique permet aussi de déterminer quels sont les mécanismes d'entrée dansl'enseignement agricole à temps plein, de cycle court et de cycle long.

2 - Une exploitation des dossiers administratifs détenus par le Centre National pour l'Aménagement des Structures des Exploitations Agricoles (C.N.A.S.E. A.) a été faite pour des travailleurs agricoles candidats aux aides à la mutation professionnelle. Il s'agit de garçons et filles qui, nés en 1945 et après, sont sortis de l'agriculture après y avoir exercé une activité pendant un temps souvent assez court et qui ont voulu, en changeant d'emploi, bénéficier des aides à la formation post-scolaire et à la conversion.

Nous remercions les responsables des Institutions où nos études ont été faites. M. ROZE et Mme CARDOU ont assuré la préparation technique et administrative du document. 
INSTITUT NATIONAL DE LA RECHERCHE AGRONOMIQUE Station diEconomie Rurale de Rennes

L'ORIENTATION SCOLAIRE ET PROFESSIONNELLE COMPAREE DES ENFANTS D'AGRICULTEURS DIUN COLLEGE DIENSEIGNEMENT SECONDAIRE ET DIUN COLLEGE AGRICOLE

Y. LAMBERT

avec la collaboration de P. DAUCE

G. JEGOUZO 

Résumé

Chapitre premier : Objectifs et conditions de réal isation de la monographie

Section 1 - But et intérêt de la monographie

- Rappel des objectifs et résultats d'une enquête effectuée en

Ille-et-Vilaine

- L'enquête monographique comme enquête complémentaire

Section 2 - Champ et méthodes d'investigation 7

- Llinstitution scolaire choisie

- Les méthodes d'investigation 7

- L'échantillon des élèves étudiés 8 9

Chapitre 2 - L'orientation scolaire comparée des élèves de l'enseignement agricole et des élèves de l'enseignement général

Section 1 - Les données scolaires, culturelles et économiques

- Le passé scolaire

- Les facteurs cul turels

- Les facteurs économiques

Section 2 - Analyse des opinions des élèves

- Quelles influences ont pesé sur l'orientation vers l'enseignement agricole?

- "Raisons" du choix ou du refus de l'enseignement agricole avancées par les élèves

- Les élèves du collège agricole sont-ils satisfaits de leur orientation scolaire et de la formation quils reçoivent dans l'enseignement agricole ?

Section 3 - Le point de vue des enseignants

- Opinion sur les raisons d'entrée au collège agricole 31

- Evolution du nombre et du niveau des candidats à la formation agricole 
Chapitre 3 - Les projets professionnels comparés des élèves de l'enseignement agricole et des élèves de l'enseignement général

Section 1 - Les projets d'entrée dans l'agricul ture et dans les secteurs para-agricoles selon la nature et le niveau de la formation en cours 36

- Opposition entre formation générale et formation agricole 36

- Les projets des élèves du collège agricole selon la dimension de l'exploitation de leurs parents 38

Section 2 - Les explications des projets professionnels 39

- Raisons de l'entrée dans l'agriculture 40

- Raisons de la non-entrée dans l'agricul ture 40

- Les interrogations de ceux qui hésitent 43

Conclusion générale 45

Liste des tableaux 47 
L'enseignement agricole secondaire a connu un développement important en France depuis quili a été réorganisé par une loi du 2 aốt 1960. Les effectifs ont par exemple doublé dans le secteur public entre 1962 et 1968. Bien que récemment rénové, ce type d'enseignement n'échappe pas à la remise en cause qui affecte l'ensemble du système scolaire. De vives critiques, venant dihorizons très divers, lui ont été faites.

La fréquence des polémiques contraste avec la rareté, sinon l'absence, d'études approfondies du fonctionnement de l'enseignement agricole et des rôles quili exerce. En effectuant une monographie en Ille et-Vilaine sur des élèves d'origine agricole, nous avons voulu commencer à étudier quelle place tient ce type d'enseignement dans l'orientation scolaire et professionnelle des enfants d'agricul teurs. Cette étude a été faite en complément d'une enquête par sondage réalisée début 1970 dans l'ensemble du département d'llle-et-Vilaine en vue d'analyser les relations entre éducation et mobilité des enfants d'origine agricole.

La monographie a pour particularité de porter sur un établissement composé de deux collèges : l'un agricole de cycles court et long, l'autre d'enseignement général. La spécificité de l'orientation scolaire des élèves (garçons) du collège agricole et de leurs projets professionnels a été analysée par comparaison avec la scolarité et les choix professionnels des élèves (garçons et filles) du collège général . La présence dans chaque collège d'élèves d'origine non agricole a permis d'étudier les mécanismes de l'orientation scolaire et professionnelle à la fois en fonction de la formation pour une origine sociale donnée, et en fonction de llorigine sociale pour une formation donnée.

La méthode d'observation a comporté deux approches. Les élèves ont fourni des faits et des opinions en remplissant eux-mêmes un questionnaire. Ces informations ont été complétées par des entretiens avec les enseignants. Si cepremier essai ne constitue pas une analyse sociologique approfondie, il permet déjà de mieux comprendre les processus d'entrée dans l'enseignement agricole et les objectifs profes sionnels poursuivis à la sortie.

En ce qui concerne les projets professionnels, les résultats de la monographie confirment et complètent l'enquête générale d'llle-et-Vilaine. Les élèves d'origine agricole du collège général, quel que soit leur niveau (de la 5 è à la 2è), ne prévoient qulexceptionnellement d'entrer dans l'agriculture. Ils s'opposent nettement aux élèves de l'enseignement agricole, tout au moins à ceux du cycle court; en effet, si $80 \%$ des élèves du cýcle court envisagent d'entrer dans l'agriculture, par contre $32 \%$ ' seulement de ceux du cycle long forment ce projet. Les choix en cycle long se portent surtout vers les professions para-agricoles et même, au niveau le plus élevé, vers des professions qui n'ont plus aucun rapport avec l'agriculture.

Ces données illustrent llopposition qui existe entre. le cycle court agricole, qui oriente vers l'agriculture en forte proportion, et le cycle 
long agricole qui oriente peu vers l'agriculture, d'autant moins que le niveau de formation est plus élevé mais d'autant plus quela dimension de l'exploitation des parents est plus grande. De façon générale, la fréquence de l'"entrée" des élèves d'origine agricole qui suivent un enseignement agricole est d'autant plus for te que le diplôme est plus bas. Ceci laisse mal augurer de l'élévation du niveau d'instruction des futurs producteurs agricoles dans les régions de faible surface. Nos observations impliqueraient que le B.T.A. oriente, par contre, plus souvent vers l'agriculture dans, les régions de grandes exploitations.

L'étude des projets professionnels en fonction, à la fois, de la formation et de l'origine sociale, précise le rôle respectif de ces deux facteurs. Quel que soit le type d'enseignement suivi, les élèves d'origine non agricole n'envisagent pas d'entrer dans l'agriculture. Cette observation n'est pas surprenante. Par contre, il est significatif de constater que dans le collège général, llattitude des enfants d'agriculteurs à l'égarddelaprófessionagricole, de même qu'à l'égard de l'enseignement agricole,tend à slidentifier à celle des élèves d'origine nonagricole. Cette constatation renforce l'influence du type de formation sur llorientation vers lemploi agricole.

Faut-il en conclure quel'enseignement agricole est facteur d'en trée dans l'agriculture? L'explication de l'entrée dans l'agriculture serait alors à rechercher dansles facteurs de l'orientation vers l'enseignement agricole. La question posée appelle deux réponses distinctes, selon le cycle suivi.

Au niveau du cycle court, le projet d'entrée dans l'agriculture est réal isé ex-ante: il intervient donc en tant que facteur de llorientation vers l'enseignement agricole. Par contre, au niveau du cycle long, même si ce projet est formé ex-ante, il se trouve reformulé ul térieurement selon le niveau de formation atteint, en liaison avec les perspectives offertes concurremment par les secteurs para-agricoles.

Cette distinction s'explique parles facteurs de l'orientation vers l'enseignement agricole. Dans le cas du cycle court, la monographie fait clairement apparaître le rôle conjoint, d'une part de l'échec scolaire, traduit par l'âge de sortie de l'écoleprimaire ou le rejet de l'enseignement général à l'issue des classes d'observation et d'orientation, d'autre part de lloffre d'emploi agricole dans l'exploitation des parents, dont la dimension est relativement élevée. Le passé scolaire des élèves du cycle long laisse supposer, au contraire, que beaucoup d'entre eux auraient pu continuer des études générales. Leur orientation vers l'enseignement agricole résulte à la fois de l'intérêt déclaré pour ce qui concerne l'agriculture, et de la crainte de l'échec suscitée par les formes abstraites de l'enseignement général, chez des élèves provenant souvent de classes de 3ème de type C.E.G..

Il y aurait ainsi, pour un certain nombre d'élèves, une relégation qui, patente dans le cas du cycle court, s'exercerait sous la forme dissimulée d'une auto-élimination dans le cas du cycle long. Il faut néanmoins se garder de considérer cette constatation comme défavorable à l'enseignement agricole, car, finalement, elle semble beaucoup moins l'expression dlune dévalorisation objective de ce type d'enseignement, que le modelé en creux des insuffisances diun enseignement général dont le contenu et la pédagogie privilégient les formes abstraites de liintel- 
ligence, et sanctionnent les inégal ités culturelles dues à l'origine sociale.

Les résultats observés dans une monographie ne sauraient être extrapolés abusivement. L'analyse desmécanismes qui, en milieu agricole, président aux choix professionnels en relation avecles choix scolaires, ainsi que l'examen de la place spécifique des deux catégories d'enseignement agricole - le court et le long - dans l'ensemble du système scolaire seront ultérieurement étendus et approfondis. 


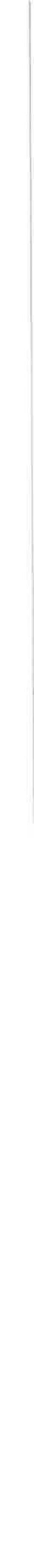


Parallèlement à une enquête statistique effectuée au printemps 1970 en Ille-et-Vilaine sur la formation suivie et les emplois exercés par un échantillon de jeunes d'origine agricole, une étude d'ordre monographique a été réal isée, à la même période, sur une institution scolaire privée située dans une petite ville du département. Cette institution a pour originalité d'être formée d'un Collège d'enseignement général et d'un Collège d'enseignement agricole. Les objectifs de l'étude de ces collèges se rapprochent et se distinguent à la fois de ceux de l'enquête par sondage (1).

Après avoir présenté les buts de la monographie, nous examinerons le champ et la méthode d'observation. Nous ne reviendrons pas sur l'utilité de l'enquête effectuée en Ille-et-Vilaine, mais il est nécessaire de rappeler ses objectifs et certains de ses résultats de façon à mieux apprécier ce que l'étude monographique peut apporter de complémentaire ou de spécifique.

(1) P. DALICE, G. JEGOUZO, Y. LAMBERT, "La formation des enfants d'agriculteurs et leur orientation hors de l'agricultureirésultats d'une enquête exploratoire en Ille-et-Vilaine", I. N.R.A. - Station d'Economie Rurale de Rennes, Janvier, 1971. 
6.

Section 1 - BUT ET INTERET DE LA MONOGRAPHIE

Rappel des objectifs et de certains résultats de l'enquête effectuée en Ille-et-Vilaine

L'enquête statistique étudie l'influence de la nature et du niveau de la formation suivie par les enfants diagriculteurs sur leur devenir professionnel, à partir d'un échantillon d'enfants appartenant aux générations 1945 à 1955. Elle distingue les transferts hors de l'agriculture qui s'effectuent par non-entrée (survenant dès le premier emploi, tout à fait au début de la vie active), et les transferts par sortie (réalisés après une période d'activité dans l'agriculture). Elle montre que l'influence de la formation s'exerce beaucoup plus lors de la non-entrée que lors de la sortie. Tout à fait en début de vie active, la plupart des enfants étudiés n'ont qulun niveau de formation primaire : cette catégorie de formation les dirigele plus souvent vers llagriculture, de même que la formation agricole, alors que la formation technique et l'enseignement général en détournent généralement.

Environ la moitié des enfants de niveau primaire qui entrent dans l'agriculture sont des apprentis : ils suivent un enseignement agricole à temps partiel (alternance ou cours post-scolaires). Cette proportion s'élève nettement avec la:surface de l'exploitation des parents. Après un temps assez court d'activité agricole, les "sorties" sont très nombreuses. Les plus nombreuxà sortir sont ceux dont la formation la plus élevée reste une formation primaire, les moins nombreux sant ceux qui ont une formation agricole. La surface de l'exploitation des parents influe sur le maintien dans l'agriculture, de la même façon que sur l'entrée, ce qui traduit le rôle important de l'offre d'emplois agricoles.

Comme la majorité des garçons et des filles qui quittent l'agriculture ont été peu scolarisés, ilsoccupent essentiellement des emplois non qualifiés. Quand ils ne se sont pas maintenus dans l'agriculture, ceux qui ont acquis un niveau de brevet d'apprentissage agricole (B. A. A.) sont devenus chez les filles, bonnes à tout faire et ouvrières non qualifiées, chez les garçons tantôt ouvriers non qual ifiés et tantôt ouvriers qualifiés du bâtiment après avoir accompli un stage de F.P. A..

L'enquête monographique, comme enquête complémentaire

L'enquête statistique saisit peu l'influence qu'exercent sur le devenir professionnel deux catégories de formation secondaire : l'enseignement secondaire général et l'enseignement agricole à temps plein, ces types de formation étant peu ou pas du tout représentés dans l'échantillon parmi les enfants ayant terminé leur scolarité à temps plein au moment des interviews. Sur un total de 540 cas $(251$ garçons et 289 filles) :

$-8,4 \%$ des garçons et $13,8 \%$ des filles ont reçu une formation secondaire générale de niveau au moins égal à la classe de $3 e$.

$-26 \%$ des garçons et $25,6 \%$ des filles ont suivi un enseignement agricole à temps partiel jusquià laprésentation du B. A. A. ou du B.P. A. .

$-4 \%$ des garçons et $9 \%$ des filles ont reçu un enseignement agricole à temps plein de niveau au moinségal au B. A. A. Mais on ne compte que 2 garçons et 1 fille ayant reçu une formation agricole de niveau supérieur au cycle court (ancien cycle 1). 
Pour les enfants dont la scolarité n'est pas terminée au moment de l'enquête (il s'agit essentiellement d'enfants nés de 1953 à 1955), les projets scolaires et professionnels ne sont pas connus. La situation scolaire des enfants des générations 1953 à 1955 à la fin de la 14ème année était la suivante :

- 39, $4 \%$ des garçons et $33,7 \%$ des filles suivaient un enseignement secondaire général, surtout en C.E.G.

$-22 \%$ des garçons et $22,1 \%$ des filles suivaient un enseignement agricole à temps partiel.

$-8,3 \%$ des garçons et $12 \%$ des filles suivaient un enseignement agricole à temps plein, principalement en cycle I.

Enfin, environ $10 \%$ de garçons et de filles fréquentaient un enseignement technique à temps plein.

Cette statistique montre qulune minorité seulement d'enfants d'agriculteurs sont scolarisés dans l'enseignement agricole à temps plein. Mais un certain nombre d'élèves de C.E.G. rejoignent cet enseignement après la classe de 3ème.

Par rapport à l'enquête par sondage, l'enquête monographique s'attache à l'étude de l'enseignement secondaire, général ou agricole à temps plein (1). Elle complète l'enquête générale en cherchant à donner des éléments de réponse aux questions suivantes, pour des élèves en cours de scolarité au moment où a lieu cette enquête générale:quelle est l'influence des types de formation sur l'entrée dans l'agriculture? Quels sont les mécanismes de l'orientation scolaire vers l'enseignement agricole ? Elle cherche à examiner quelles sont les raisons des choix scolaires et professionnels au travers des opinions des élèves et des enseignants.

Section II - CHAMP ET METHODES DIINVESTIGATION

Après avoir expliqué le choix de l'institution scolaire et la méthode dlobservation, nous présenterons les caractéristiques de lléchantillon étudié.

\section{L'institution scolaire choisie}

L'institution choisie présente plusieurs conditions favorables à la réalisation du type d'étude entrepris:

- Elle appartient à une petite ville située dans une zone essentiellement rurale.

(1) On trouvera, à la fin du chapitre 1, des tableaux présentant l'orgànisation de l'enseignement agricole. 
8.

- Elle comprend un collège d'enseignement général et un collège d'enseignement agricole (C.E.A.) juxtaposés. Ceci facilitel'étude des mécanismes de l'orientation vers l'enseignement agricole ainsi que l'analyse comparative des projets scolaires et professionnels. Notons que le collège général ne comporte pas de classes terminales et quili est mixte. Le collège agricole comporte toutes les classes de cycle court et de cycle long (1) et n'est ouvert qu'aux garçons.

- Il s'agit de collèges privés, prépondérants en Bretagne en milieu rural, en particulier dans le domaine de l'enseignement agricole (2).

- Enfin, le responsable de l'enquête a donné des cours au collège agricole, ce qui lui a permis d'être en contact direct et suivi avec l'institution.

\section{Les méthodes d'investigation}

L'enquête repose sur deuxvoies d'approche. Nous avons fait remplir un questionnaire auxélèves, en notre présence, classe par classe. Ces renseignements recueillis en mars 1970 ont été complétés par des entretiens avec certains enseignants et par des observations relevées dans le cadre de la présence participante du responsable de l'enquête.

Le questionnaire a été rempli par tous les élèves du C.E. A. (collège d'enseignement agricole) et par les élèves du collège général des classes de 5è (sections "générale" et de "transition"), des classes de 4 è, 3è et 2 (de toutes les sections). Ces classes sont celles où une orientation vers l'enseignement agricolepourrait se manifester ou pourrait avoir été refusée.

La première partie du questionnaire porte sur le cursus scolaire de l'élève, la situation scolaire ou professionnelle de ses frères et soeurs, la formation et l'activité professionnelle de ses parents. Une seconde partie pose une série de questions ouvertes ou fermées sur les mécanismes de l'orientation scolaire, les projets professionnels et, pour les élèves du C.E. A., le jugement porté sur l'enseignement agricole. Les élèves d'origine non-agricole du collège général constituent en quelque sorte un groupe témoin. Les informations obtenues sont de bonne qualité pour les questions fermées, mais les réponses aux questions ouvertes sont souvent pauvres car nous avons dû "fairellremplir les questionnaires en un tempslimité. En outre les projets professionnels sont souvent incertains chez les enfants les plus jeunes.

Les entretiens avecles enseignants ont eu lieu lors de la mise au point du questionnaire et de la présentation des résultats provisoires de l'enquête. Enfin, la présence participante permet de rendre plus vraie et plus riche la relation entre la recherche et le terrain : il en résulte une interaction qui suscite sans cesse de nouvelles questions et de nouvelles interprétations.

(1) Dans llenseignement public, les "collèges agricoles" au sens strict n'ont pas de cycle long.

(2) Cf. "Caractéristiques du département dans lequel l'enquête a été effectuéell - Section 2 du chapitre 1 de l'enquête génèrale. 
Les raisons mêmes du choix de l'institution et des méthodes d'observation livrent les limites de l'enquête. Les éléments d'approche sociologique ont avant tout pour but d'éclairer la compréhension des mécanismes et relations appréhendés à partir des données d'ordre statistique. Il aurait été nécessaire d'effectuer des entretiens auprès dlun échantillon de parents d'élèves. Par ailleurs, avant de tenter des généralisations, nous devrons au moins confronter nos conclusions avec celles de l'enquête générale Ille-et-Vilaine pour les points communs. Le rapprochement est permis car la grande majorité des élèves interrogés est originaire du département dillle-et-Vilaine. En outre, les trois quarts de ces élèves appartiennent auxgénérations prises en compte dans l'enquête statistique.

La présentation de la répartition de notre population selon la formation en cours et llorigine sociale permettra de mieux délimiter le champ de l'étude.

\section{L'échantillon des élèves étudiés}

Le tableau $n^{0} 1$ présente les effectifs des élèves du collège agricole, le tableau $n^{\circ} 2$ celui des élèves au collège général.

Tableau n¹ - Effectifs des élèves du collège agricole (tous garçons)

\begin{tabular}{|c|c|c|c|}
\hline cycle & classe & section & effectif \\
\hline cycle court & 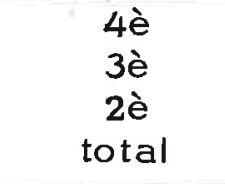 & & $\begin{array}{r}21 \\
7 \\
11 \\
39\end{array}$ \\
\hline cycle long & $\begin{array}{c}2 \text { è } \\
\text { lère } \\
\text { terminale } \\
\text { total } \\
\end{array}$ & $\begin{array}{l}\text { B.T.A. O. } \\
\text { B. T. A. } \\
\text { B.T.A. } \\
\text { Bacc. DI }\end{array}$ & $\begin{array}{r}22 \\
17 \\
11 \\
20 \\
7 \\
77\end{array}$ \\
\hline total & & & 116 \\
\hline
\end{tabular}

On relève que les élèves du cycle long sont deux fois plus nombreux que ceux du cycle court. Notons à ce propos qulen 1967-1968, $73 \%$ des garçons scolarisés dans l'enseignement agricole (à temps plein ou à temps partiel) en Ille-et-Vilaine, l'étaient dans le cycle I (1).

(1) Chambre Départementale d'Agricul ture, Rapport sur l'enseignement et la formation professionnelle agricole, ronéo, 1969, page A10. 
10.

Tableau $n^{\circ} 2$ - Effectifs des élèves du collège général

\begin{tabular}{|c|l|c|c|c|}
\hline \multirow{2}{*}{ classe } & \multirow{2}{*}{ section } & \multicolumn{3}{|c|}{ nombre d'élèves } \\
\cline { 2 - 5 } 5è & garçons & filles & total \\
\hline \multirow{5}{*}{ 4è } & Orientation & 10 & 14 & 24 \\
& Transition & 11 & 13 & 24 \\
& Longue & 24 & 28 & 52 \\
& Courte & 14 & 16 & 30 \\
& Pratique & 15 & 11 & 26 \\
& Longue & 25 & 32 & 57 \\
& Courte & 5 & 12 & 17 \\
& Pratique & 10 & 10 & 20 \\
& Classique et mo- & 15 & 15 & 30 \\
& derne & 129 & 151 & 280 \\
\hline
\end{tabular}

Compte tenu des objectifs de l'étude, nous distinguerons seulement, au titre de l'origine sociale, les élèves d'origineagricole (enfants d'agricul teurs exploitantset de salariés agricoles) et les élèves d'origine non agricole. Cependant, afin de mieux caractériser la population d'élèves étudiée nous donnerons une décontraction de l'origine sociale selon les diverses catégories socio-professionnelles que nous avons distinguées lors du dépouillement.

La proportion des enfants d'agriculteurs est beaucoup plus élevée dans l'enseignement agricole $(87 \%)$ que dans l'enseignement général, oùlespourcentages sont de $36 \%$ pour les garçons et de $40 \%$ pour les filles. L'importance relative de l'origine agricole est encore plus marquée dans le cycle court de l'enseignement agricole que dans le cycle long ; cette hiérarchie semble suggestive. Si dans l'enseignement général, la proportion des enfants d'agricul teurs est plus faible dans les sections pratiques que dans les autres sections, clest que ceux-ci tendent à rejoindre le cycle court agricole plutôt que d'entrer en 4è et 3è pratiques (1). La profession des parents constitue nettement llun des facteurs généraux de l'orientation vers l'enseignement agricole.

L'origine sociale détaillée montre que le recrutement de liinstitution se fait surtout dans les classes populaires et les classes moyennes. Les élèves issus des catégories "agriculteurs" "ouvriers et personnel de service", "commerçants" représentent $78 \%$ de llensemble des élèves du C.E.G. 'L'importance du public issu de couches sociales généralement défavorisées en face de l'enseignement n'est pas sans atténuer les effets de la sélection liés à l'origine sociale, à lintérieur de

(1) La forte proportion dlenfants d'agriculteurs observée en classe de 5 è longue tient au fait que nous avons retenu dans l'échantillon la classe fonctionnant selon le type C.E.G.. 
Tableau $n^{\circ} 3$ - Origine sociale des élèves selon la nature et le niveau de l'enseignement suivi (en \%)

\begin{tabular}{|c|c|c|c|c|c|c|c|c|}
\hline \multirow[b]{2}{*}{ Origine sociale } & \multicolumn{5}{|c|}{ Collège général } & \multicolumn{3}{|c|}{ Collège agricole } \\
\hline & $\begin{array}{l}\text { 5ème } \\
\text { longue }\end{array}$ & $\begin{array}{c}5 \text { ème de } \\
\text { transition } \\
\text { et } 4 \text { ème et } \\
\text { 3ème pra- } \\
\text { tiques }\end{array}$ & $\begin{array}{l}\text { 4ème et } \\
\text { 3ème } \\
\text { courtes }\end{array}$ & $\begin{array}{l}\text { 4ème et } \\
\text { 3ème Lon- } \\
\text { gues et } \\
\text { 2ème }\end{array}$ & Ensemble & $\begin{array}{l}\text { Cycle } \\
\text { court }\end{array}$ & $\begin{array}{l}\text { Cycle } \\
\text { long }\end{array}$ & Ensemble \\
\hline ORIGINE AGRICOLE & 71 & 30 & 40 & 36 & 38 & 92 & 84 & 87 \\
\hline ORIGINE NON AGRICOLE & 29 & 70 & 60 & 64 & 62 & 8 & 16 & 13 \\
\hline $\begin{array}{l}\text { - ouvriers, personnel de ser- } \\
\text { vice }\end{array}$ & & 30 & 19 & 18,5 & 20 & 2,5 & - & 1 \\
\hline $\begin{array}{l}\text { - Employés de bureau et com- } \\
\text { merce }\end{array}$ & & 3 & 4 & & 4 & - & - & - \\
\hline $\begin{array}{l}\text { - Patrons de llindustrie et du } \\
\text { commerce }\end{array}$ & & 14 & 26,5 & 22 & 20 & - & 5,5 & 3 \\
\hline $\begin{array}{l}\text { - Cadres, professions libérales } \\
\text { - Autres et sans profession }\end{array}$ & & $\begin{array}{r}4 \\
19\end{array}$ & $\begin{array}{l}8,5 \\
2\end{array}$ & $\begin{array}{l}10 \\
8,5\end{array}$ & $\begin{array}{r}8 \\
10\end{array}$ & 2,3 & $\begin{array}{l}4 \\
6,5\end{array}$ & $\begin{array}{l}3 \\
6\end{array}$ \\
\hline TOTAL & 100 & 100 & 100 & 100 & 100 & 100 & 100 & 100 \\
\hline$(\mathrm{N})$ & $(24)$ & $(70)$ & (47) & (139) & $(280)$ & (39) & $(77)$ & $(116)$ \\
\hline
\end{tabular}


ANNEXE 1 - STRUCTURE ACTUELLE DE L'ENSEIGNEMENT AGRICOLE

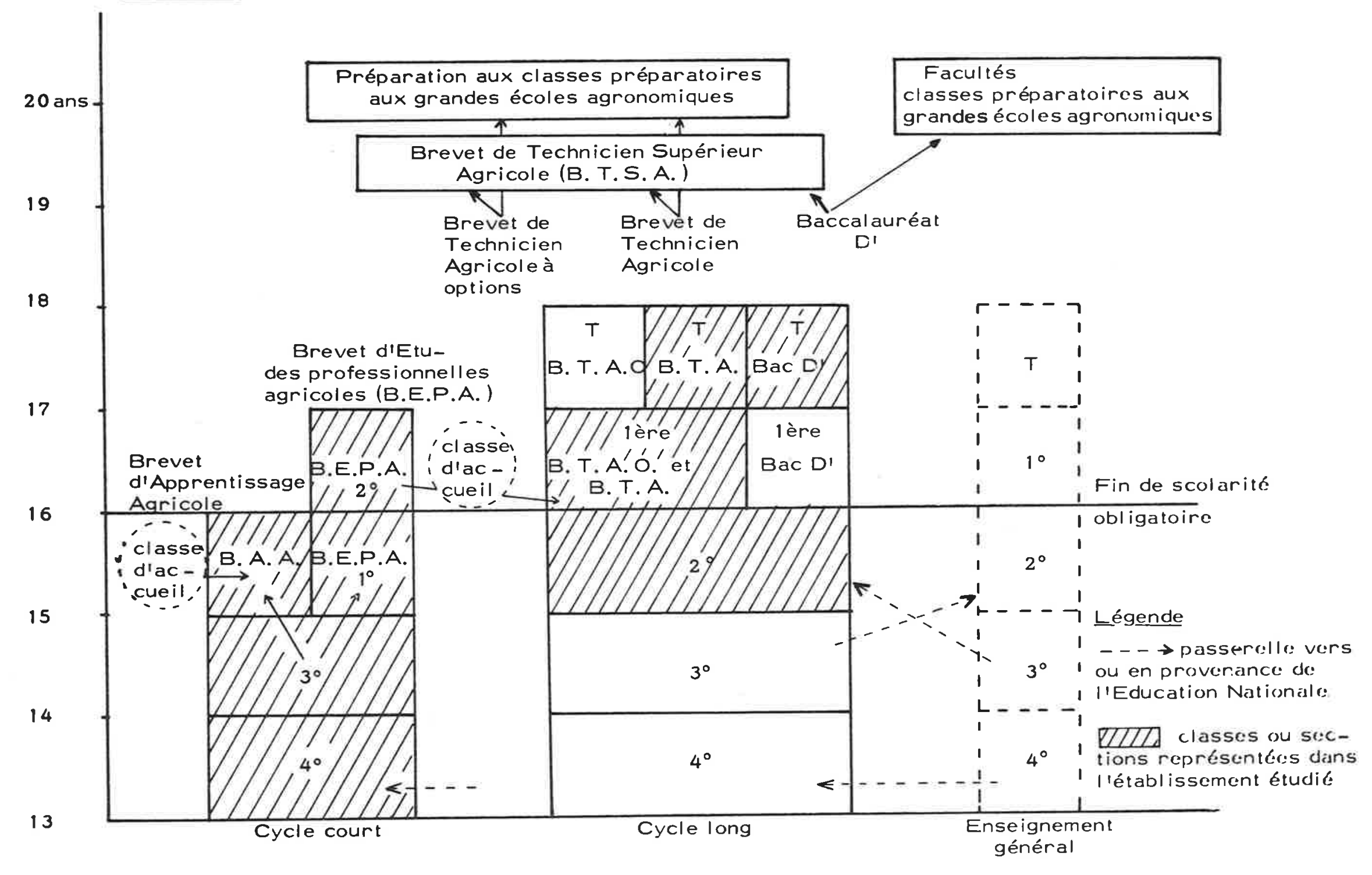


ANNEXE 2 - STRUCTURE DE L'ENSEIGNEMENT AGRICOLE AVANT L'ANNEE SCOLAIRE 1969-1970

Brevet de

Technicien

Supérieur

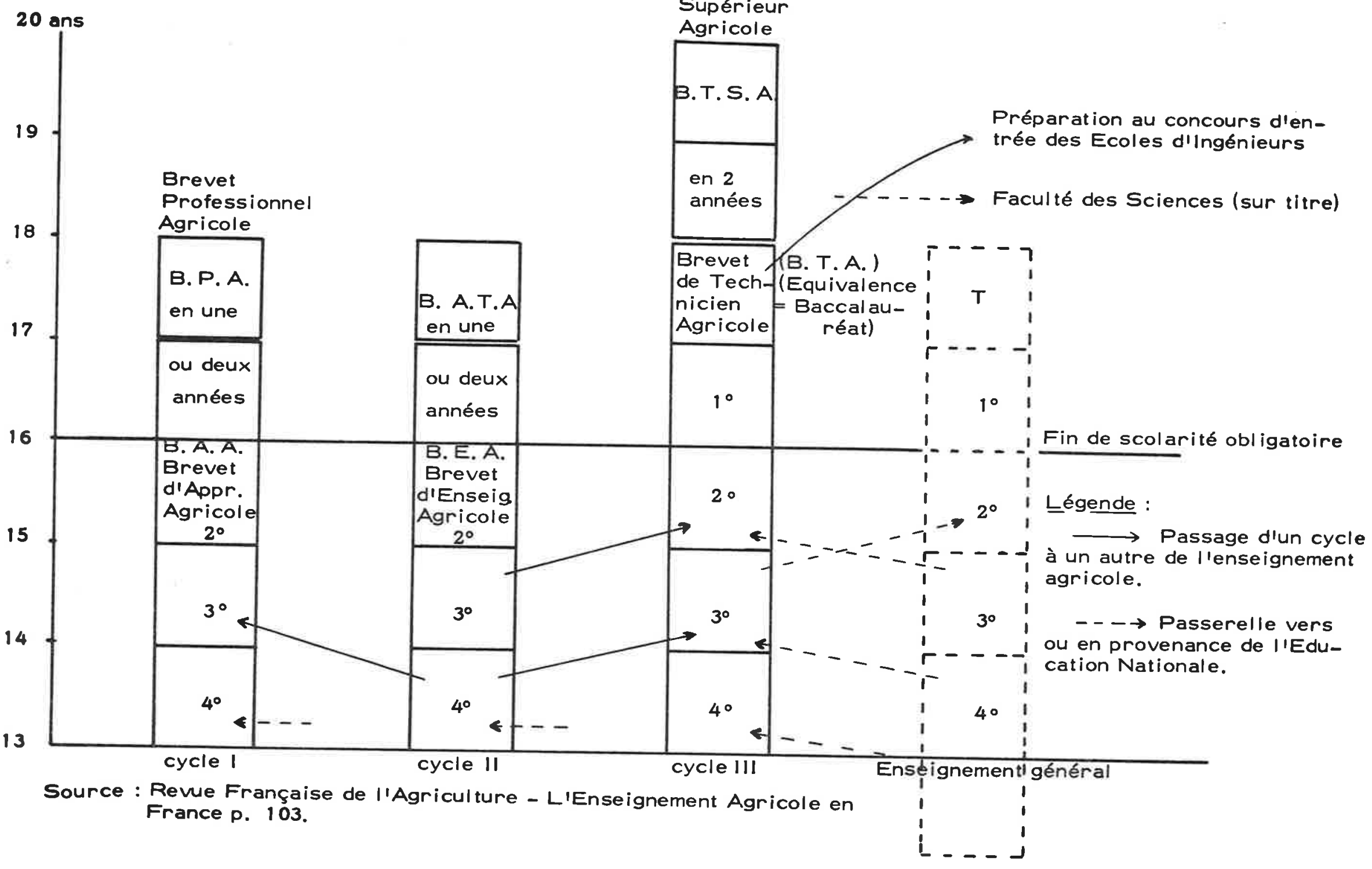


14.

l'établissement : le climat, ainsi que l'adéquation du "message" y sont plus favorables (1).

Les observations faites en matière d'orientation scolaire et d'orientation professionnelle seront présentées dans deux chapitres successifs. Cette distinction est en partie arbitraire dans la mesure où scolarité et perspective professionnelle sont à la fois cause et conséquence l'une de l'autre.

(1) On retrouve néanmoins des inégal ités sensibles, fondées sur l'origine sociale, dans la fréquentation des différentes sections. Ainsila proportion d'élèves appartenant aux C.S.P. "louvriers et personnel de service"l est plus grande dans les sections de transition et pratiques ; inversement, les élèves issus des C.S.P. "cadres supérieurs et professions l ibérales" sont "sur-représentés"dans les sections classiques et modernes longues. 
On sait que la réussite scolaire à l'école primaire, les taux de scolarisation secondaire, et les tauxd'accès aux différents types d'enseignement secondaire sont inégaux selon les origines sociales, en particulier parce que leniveau culturel familial est inégal socialement (1). Partant dlun échantillon d'élèves de l'enseignement secondaire-agricole et général - nous cherchons à répondre à la question : pourquoi certains enfants d'agriculteurs s'orientent-ils vers l'enseignement agricole et d'autres vers l'enseignement général ?

Faut-il en rechercher l'explication dans les inégalités de niveau culturel des familles qui existeraient à l'intérieur de la catégorie sociale des agriculteurs ? Le niveau de formation des parents agriculteurs est généralement bas. Dèslors, il est probable que le rôle du facteur culturel familial, saisi par llintermédiaire du diplôme, se manifeste peu dans l'échantillon étudié, donnant ainsi au rôle des facteurs économiques un poids important que nous tenterons de cerner à partir de la variable "dimension del'exploitation" (surface etprésence ou non de productions spécialisées), en liaison avec le système dlattributions des bourses.

La dépense d'éducationprésentant certains des caractères d'une dépense d'investissement, on peut, pour rendre compte du choix dlun type donné de formation se référer à la logique du choix de l linvestissement. Parmi les divers investissements en éducation sera choisi celui qui apparaitra aux parents comme le plus rentable compte tenu de son coût

(1) Voir à ce sujet en particulier :

- A. SAUVY et A. GIRARD, Les diverses classes sociales devant l'enseignement - Mise au point générale des résultats, Population $n^{\circ} 2$ - mars avril 1965, pp. 205-232.

- P. BOURDIEU, La transmission de l'héritage culturel, in DARRAS, Le partage des bénéfices, Paris, Ed. de minuit, 1966, pp. 387-405. 
16.

et du risque attaché à son résul tat économique et social. Le risque concerne la probabilité d'obtenir le diplôme qui sanctionne la formation sui vie et la probabilité d'accéder à un emploi grâce à ce diplôme (1). Cette interprétation de llorientation de formation tient compte de facteurs liés les uns à la réussite scolaire, les autres aux perspectives d'emploi et à la réussite sociale.

Le rôle que les déterminismes culturels scolaires et économiques exercent dans l'orientation vers l'enseignement agricole, apparaît-il à l'examen de données de fait et d'opinions des élèves et des enseignants?

Section 1 - DONNEES SCOLAIRES, CULTURELLES ET ECONOMI-
QUES

1 - Le passé scolaire

Les élèves du cycle agricole court et ceux du cycle long sont le plus souvent issus de catégories d'établissements et de sections qui, au sein du Ministère de l'Education Nationale, sont considérées comme les moins "nobles" :

$\begin{array}{cc}\text { - cycle court : Enseignement primaire } & : 50 \% \\ \text { Classe de 5è de transition } & : 15 \% \\ \text { Classe de 5ème moderne courte } & : 19 \% \\ \text { Classe de 5ème moderne longue } & : 6 \% \\ \text { Classe de 4ème } & : 10 \%\end{array}$

$\begin{array}{cc}\text { - cycle long: Ancien 2è cycle agricole } & : 25 \% \\ \text { 1er cycle C.E.G. } & : 57 \% \\ \text { ler cycle C.E.S. } & : 17 \% \\ \text { Classe de seconde générale } & : 1 \%\end{array}$

Les élèves du cycle long se recrutent essentiellement à l'issue de la classe de 3ème de type C.E.G. . Par contre, le cycle court reçoit en classe de 4ème une moitié d'élèves de l'enseignement primaire, et un tiers d'élèves du cycle d'orientation (classes de 5 ème courtes) le plus souvent après un redoublement en 6ème ou en 5ème. Ces niveaux différents d'accès à l'enseignement agricole introduisent une nette distinction entre lesélèves qui rejoignent le cycle court agricole et ceux qui s'orientent vers le cycle long. L'un et l'autre cas renvoient eux-mêmes aux résultats scolaires obtenus à l'école primaire, car clest dès ce stade que le devenir scolaire se dessine. 
Nous caractériserons la scolaritéprimaire par l'âge de sortie de l'école primaire. Ce critère est imparfait, mais, comme l'écrivent MM. GIRARD et BASTIDE, "l'âge résume en quel que sorte la scolarité passée des élèves et constitue un signe impor tant de leurs aptitudes (...) L'enfant qui réussit très bien au Cours Moyen 2 ème année et qui est arrivé jeune a devant lui un avenir scolaire tout tracé. Au contraire, celui qui y parvient tard et n'y réussit pas n'est pas destiné à poursuivre des études prolongées" (1).

Tableau n4 - Age de sortie de l'école primaire selon l'orientation scolaire et llorigine sociale (en \%)

\begin{tabular}{|l|c|c||c|c|}
\hline \multicolumn{1}{|c|}{$\begin{array}{c}\text { Origine } \\
\text { sociale }\end{array}$} & \multicolumn{2}{|c||}{$\begin{array}{c}\text { Collège général } \\
\begin{array}{l}\text { Age de } \\
\text { sortie }\end{array}\end{array}$} & $\begin{array}{c}\text { C. E. A. (origine } \\
\text { agricole) }\end{array}$ \\
\cline { 2 - 5 } & $\begin{array}{l}\text { Origine } \\
\text { agricole }\end{array}$ & $\begin{array}{c}\text { origine } \\
\text { non agr. }\end{array}$ & $\begin{array}{c}\text { cycle } \\
\text { court }\end{array}$ & $\begin{array}{c}\text { cycle } \\
\text { long }\end{array}$ \\
\hline 11 ans et moins & 37 & 44 & 17,5 & 62 \\
12 ans & 50,5 & 36 & 32 & 29 \\
13 ans & 8,5 & 15 & 17,5 & 7 \\
14 ans et plus & 4 & 5 & 33 & 2 \\
Total & 100 & 100 & 100 & 100 \\
\hline
\end{tabular}

Si l'on considère comme "normale" la sortie de l'école primaire à l'âge de 11 ans, on constate des retards scolaires assez importants lors de l'entrée dans l'enseignement secondaire, quelles que soient la nature de l'enseignement oul'origine sociale. II est cependant frappant de relever l'ampleur des handicaps accumulés, à ce stade, par les enfants dlagricul teurs du cycle court du C.E. A. . Allopposé, ceuxdu cycle long se distinguent par la situation la plus favorable de l'ensemble de l'échantillon; néanmoins la moitié des élèves du cycle long ont redoublé une classe avant d'entrer au collège agricole.

Le tableau $n^{\circ} 5$ complète ces observationspar une comparaison entre les niveaux d'enseignement,pour tous les élèves.

On relève une similitude entre les retards scolaires des élèves du cycle court et ceux des élèves des sections pratiques ou de transition. Ces deux catégories d'enseignement constituent des voies de rélégation à l'intérieur du système scolaire. Sur vingt sept élèves du cycle court qui se sont présentés au Certificat d'Etudes Primaires, dix ont subi un échec. Tout ceci fait présumer que l linfluence de la réussite à l'école primaire sur l'orientation vers l'enseignement agricole est forte, et qulelle s'exerce d'une façon différente entre les deuxcycles. Le cycle

(1) Orientation et sélection scolaires, "Population" et I'Enseignement, Paris, PUF, 1970 , p. 365-470, page 440. 
18.

court serait ainsi le refuge dlune partie des élèves les moins "aptes" alors que le cycle long recrute des élèves qui ont terminé des études générales de 1 er cycle en obtenant généralement le B.E.P.C. (sur 57 élèves du cycle long qui llont passé, 10 ont échoué). Pourquoi, parmi les enfants d'agriculteurs qui échouent ou qui réussissent dans le ler cycle de l'enseignement général, certains s'orientent-ils vers l'enseignement agricole ?

Tableau n॰5 - Age de sortie de l'école primaire selon la nature et le niveau de l'enseignement suivi (en \%)

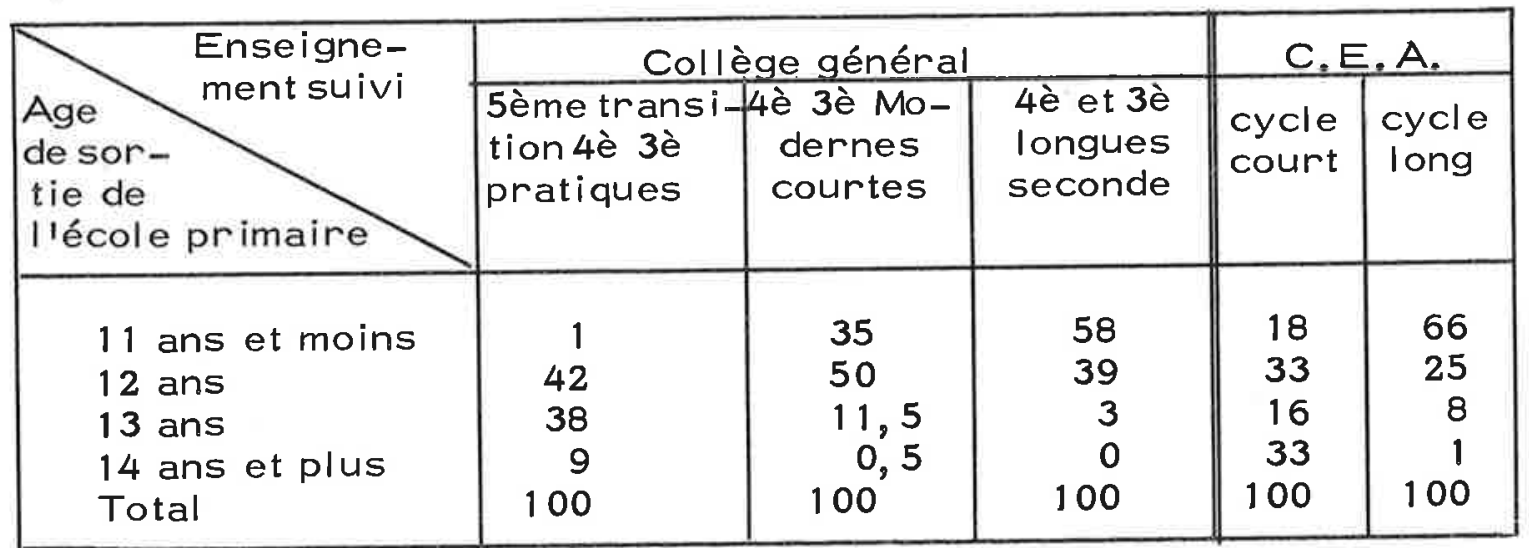

\section{2 - Les facteurs cul turels}

Il resterait à analyser les facteurs de la réussite scolaire au niveau de l'école primaire, facteurs qui sont d'ordre culturel et d'ordre économique, les deux étant liés. Les résul tats de l'enquête permettentils de montrer quel rôle joue le niveau de formation des parents sur l'orientation vers l'enseignement agricole ? Ce rôle pourrait s'exercer en particulier par lintermédiaire de l'âge de sortie de l'école primaire. Les données sont les suivantes :

Diplôme le plus élevé du père (Quelle que soit llorigine sociale)

$\%$ de sorties à 11 ans et moins

Néant

C. E.P.

Diplồmes techniques (surtout C.A.P.)

B.E.P.C.

Baccal auréat ou études supérieures

$34 \%$
$41 \%$
$47 \%$
$50 \%$
$70 \%$

Il faut d'abord faire remarquer que les élèves des divers types d'enseignement appartiennent parfois aux mêmes familles. En outre la quasi-totalité des parents agriculteurs ont quitté l'écoleprimaire à l'âge de 12 ans avec ou sans C.E.P.. Il n'est pas possible par conséquent de déterminer l'influence de la formation du père sur llorientation vers l'enseignement agricole. 
Peut-on recourir à un autre critère pour caractériser le niveau culturel des parents agriculteurs ? Etant donné quelaplupart des agriculteurs se sont "formés sur le tas", par la pratique de leur métier, nous nous sommes demandés si l'exercice des responsabilités hors de l'exploitation n'était pas susceptible de fournir des éléments plus significatifs. Les parents des élèves d'origine agricole ont été répartis selon qulils exerçaient ou avaient exercé des responsabilités dans une organisation familiale, professionnelle, administrative, syndicale, politique ou autre. Les cas de responsabilitè sont de 3 types : responsabilité du père, de la mère ou des deuxà la fois. Les pourcentages de cas de responsabilité par rapport au nombre de familles d'agriculteurs sont de $32 \%$ au C.E.G., de $45 \%$ dans le cycle court agricole et de $50 \%$ dans le cycle long agricole.

Ces différences de fréquences selon les types d'enseignement ne sont pas faciles à interpréter. II semble que les cas de responsabilité traduisent une meilleure ouverture des parents et une certaine "confiancell dans l'agriculture, car il s'agit surtout de responsabilitésprofessionnelles. De plus les prises de responsabilité ne sont pas indépendantes de la surface de l'exploitation. Nous ne sommes pas en mesure de préciser le rôle respectif de ces deuxéléments, mais il est frappant, en tout cas, de relever la proportion élevée de parents ayant des responsabilités parmi ceux qui envoient leurs enfants en C.E.G. et surtout dans l'enseignement agricole long; cette attitude:n'est probablement pas dénuée dlune recherche de prestige, pour certains.

Ainsi, il n'apparaît pas de différences culturelles vraiment nettes entre les diverses familles des élèves de l'enseignement général et de l'enseignement agricole. Si de telles différences existaient réellement, elles se reflèteraient dans le type d'enseignement suivi par les frères et soeurs scolarisés dans le secondaire et le supérieur lors de l'enquête. Le tableau $n^{\circ} 6$ montre que les répartitions diffèrent peu.

Tableau $n^{\circ} 6$ - Frères et soeurs des enfants d'agriculteurs du Collège Général ou du C.E.A. : type d'enseignement suivi audelà du primaire par ceux qui sont en cours de scolarité

\begin{tabular}{|l|c|c|c|c|}
\hline Type d'enseignement & \multicolumn{2}{|c|}{ C. E. A. } & \multicolumn{2}{|c|}{$\begin{array}{l}\text { Collège } \\
\text { Général }\end{array}$} \\
\cline { 2 - 6 } & Nbre & $\%$ & Nbre & $\%$ \\
\hline Général C.E.G. & 48 & 32 & 42 & 39,3 \\
Général C.E.S., Lycée & 59 & 39,3 & 40 & 37,4 \\
Technique court et long & 12 & 8 & 9 & 8,4 \\
Agricole cycle court & 13 & 9,7 & 6 & 5,6 \\
Agricole cycle long & 12 & 8 & 6 & 5,6 \\
Enseignement supérieur & 6 & 4 & 4 & 3,7 \\
Total & 150 & 100 & 107 & 100 \\
\hline
\end{tabular}

Nos données d'enquête peuvent être insuffisantes pour caractériser le milieuculturel familial et pour mettre en lumière son influence éventuelle sur llorientation scolaire ; il faudrait sur ce point réaliser des interviews de famille. L'information recueill iepermet par contre d'exa- 
20.

miner le rôle de facteurs économiques liés au coût de la formation et aux perspectives de débouchés professionnels.

\section{3 - Les facteurs économiques}

Alors que les bourses agissent uniquement sur le coût de la scolarité, la dimension d'exploitation peut avoir un double effet. Quand elle augmente, les revenus de la famille s'élèvent (en général), ce qui peut permettre dlune part de financer une scolaritéplus longue et d'autre part d'offrir des perspectives intéressantes de reprise. Nous faisons l'hypothèse que clest l loffre d'emploi qui allaction la plus importante sur le choix du type de formation.

\section{- La dimension de l'exploitation}

La dimension de l'exploitation a été caractérisée non seulement par la surface agricole utile (S. A. U.) mais par la présence ou non de productions spécialisées (1), pour tenir compte de certains aspects de lintensification de la production.

L'enquête statistique effectuée en Ille-et-Vilaine montre que l'augmentation de superficie s'accompagne dlune élévation générale du taux de scolarisation après liâge de la scolarité obligatoire et d'une élévation relativement plus nette de taux de scolarisation dans l'enseignement agricole. Toutefois, elle n'isole pas l'enseignement agricole à temps plein. Les observations faites dans la monographie (tableau $n^{\circ} 7$ ) complètent et confirment celles de l'enquête statistique.

Tableau $n^{\circ} 7$ - Dimension de l'exploitation des parents selon la nature de l'enseignement suivi par les enfants $(\%)$

\begin{tabular}{|c|c|c|c|}
\hline \multirow{2}{*}{$\begin{array}{ll}\text { S. A.U. } & \text { Ensei- } \\
\text { et spécial isation } & \text { gnement } \\
\end{array}$} & \multirow{2}{*}{$\begin{array}{l}\text { Collège } \\
\text { général }\end{array}$} & \multicolumn{2}{|c|}{ C.E. A. } \\
\hline & & $\begin{array}{l}\text { cycle } \\
\text { court }\end{array}$ & $\begin{array}{r}\text { cycle } \\
\text { long }\end{array}$ \\
\hline $\begin{array}{l}\text { moins de } 10 \text { ha } \\
10 \text { à } 20 \text { ha } \\
20 \text { ha et plus } \\
\text { Total }\end{array}$ & $\begin{array}{r}14 \\
28 \\
58 \\
100\end{array}$ & $\begin{array}{r}0 \\
23 \\
77 \\
100\end{array}$ & $\begin{array}{r}3 \\
26 \\
71 \\
100\end{array}$ \\
\hline $\begin{array}{l}\text { Pourcentages d'exploitations } \\
\text { ayant des productions spé- } \\
\text { cialisées }\end{array}$ & $20 \%$ & $52 \%$ & $45 \%$ \\
\hline
\end{tabular}

(1) Définies selon les normes minima suivantes (cas rencontrés)

- 50 porcs ou 7 truies

. 50 veaux

. 20 bovins d'engraissement

. 50 brebis
- 0,10 ha de serres

- I ha de maraichage de plein champ 
Les élèves d'origine agricole du C.E. A. proviennent plus sou vent que ceux du collège général des exploitations qui ont les surfaces les plus grandes et les productions les plus intensives. Les dépenses d'éducation n'étant pas connues, on peut seulement déduire des faits précédents qu'il y a une influence des possibilités d'emploi agricole sur le choix de l'enseignement agricole à temps plein.

\section{- Le système des bourses}

Comme le département dillle-et-Vilaine est classé "zone de rénovation rurale", les attributions de bourses aux enfants diagricul teurs y sont nombreuses et dlun montant plus élevé. Rappelons que les bourses nationales (1) de l'enseignement général ont un montant qui varie de 2 parts annuelles à 10 parts annuelles (part annuelle : $117 \mathrm{~F}$, pour 19691970). Elles sont majorées dlune part annuelle en zone de rénovation rurale, majoration qui peut atteindre deux à trois parts annuelles chez les internes à partir de la classe de seconde. Quant aux bourses d'enseignement agricole (2) qui sont délivrées par le Ministère de l'Agriculture, leur montant peut correspondre à une bourse entière $(960 \mathrm{~F})$, ou à une fraction $(3 / 4,1 / 2,1 / 4)$. En zone de rénovation rurale, elles peuvent être majorées du1/8ème de leur montant pour les enfants d'agricul teurs et d'un autre $1 / 8$ ème s'il $y$ a internat.

Pour l'année scolaire 1969-70, 32 bourses ont été accordées à des élèves du C. E. A., dont 31 enfants diagriculteurs et un fils de salarié agricole. Les bourses accordées aux enfants d'agriculteurs se répartissent comme suit en fonction de leur montant (3).

Tableau n॰8 - Bourses accordées aux enfants d'agriculteurs du C. E. A.

\begin{tabular}{|l|c|c|c|}
\hline $\begin{array}{l}\text { cycle } \\
\text { diétude } \\
\text { Montant de } \\
\text { la bourse }\end{array}$ & $\begin{array}{c}\text { cycle } \\
\text { court }\end{array}$ & $\begin{array}{c}\text { cycle } \\
\text { long }\end{array}$ & $\begin{array}{l}\text { Ensemble } \\
\text { C.E. A. }\end{array}$ \\
\hline $960 \mathrm{~F}($ entière) & 1 & 5 & 6 \\
$720 \mathrm{~F}(3 / 4)$ & 0 & 5 & 5 \\
$480 \mathrm{~F}(1 / 2)$ & 5 & 8 & 13 \\
$360 \mathrm{~F}(1 / 4+1 / 8)$ & 2 & 1 & 1 \\
$240 \mathrm{~F}(1 / 4)$ & 8 & 23 & 6 \\
Nombre total de bourses & $22 \%$ & $35 \%$ & $31 \%$ \\
\hline Proportion de boursiers & & & \\
\hline
\end{tabular}

(1) Le collège général ayant passé un contrat d'association est habilité à les recevoir.

(2) Le C.E.A. les reçoit en tant qu'établissement reconnu.

(3) Clest compte tenu de la rareté des informations publiées sur les attributions de bourses que nous faisons état des quelques données recueillies sur ce point dans notre enquête. 
La quasi-totalité des bourses accordées aux élèves du collège général sont des bourses nationales (certains élèves ont ob tenu une bourse départementale). Le tableau $n^{\circ} 9$ donnela répartition des bourses nationales obtenues par les élèves des classes de 4è, 3è et 2 è du C.E.S. selon leur montant et selon l'origine sociale des enfants. Pour la classe de 5è nous nlavions pas les données de toutes les sections.

Tableau n9 - Bourses nationales accordées aux élèves des classes de 4 è, 3è et 2 è du collège général

\begin{tabular}{|l|c|c|c|}
\hline $\begin{array}{c}\text { Origine } \\
\text { sociale }\end{array}$ & $\begin{array}{c}\text { élèves } \\
\text { d'origine } \\
\text { agricole }\end{array}$ & $\begin{array}{c}\text { élèves } \\
\text { d'origine } \\
\text { nonagri- ensemble } \\
\text { cole }\end{array}$ & $\begin{array}{c}\text { ensèves } \\
\text { des } \\
\text { la bourse }\end{array}$ \\
\hline 8 parts et plus (936 F etplus) & 5 & 3 & 8 \\
6 ou 7 parts (702 F - 819 F) & 18 & 16 & 34 \\
4 ou 5 parts (468 F-585 F) & 25 & 25 & 50 \\
2 ou 3 parts (234 F - 351 F) & 21 & 33 & 54 \\
Nombre total de bourses & 69 & 77 & 146 \\
\hline Proportion de boursiers & $82 \%$ & $52 \%$ & $62 \%$ \\
\hline
\end{tabular}

La proportion globale des boursiers varie du simple au double entre le C.E.A. et l'échantillon retenu du collège général. Cette différence importante doits'analyser en tenant compte de l'origine sociale des élèves et de la surface des exploitations.

En ce qui concerne les enfants d'agriculteurs, la proportion de boursiers est de $31 \%$ dansle C.E. A. et de $82 \%$ dans le collège général A liintérieur de chaque classe de surface, les proportions respectives sont les suivantes : C.E. A. Collège général

$\begin{array}{lll}\text { - Exploitations de moins de } 20 \text { ha } & 70 \% & 95 \% \\ \text { - Exploitations de } 20 \text { ha et plus } & 16 \% & 70 \%\end{array}$

A catégorie de surface égale, laproportion de boursiers est nettement plus forte au collège général qu'au C. E. A. mais il n'apparaît pas de différence sensible dans le montant des bourses accordées, entre les deux établ issements, ni selon le régime des études (pensionnat ou demipensionnat). Les externes ont des bourses dlun montant inférieur mais ils sont très peu nombreux parmi les enfants d'agriculteurs. Il semble donc que les enfants d'agriculteurs du collège général obtiennent plus facilement des bourses que ceux du C.E.A.. Clest tout au moins ce que pensent les dirigeants des deux établissements.

On ne peut cependant pas en conclure que le système d'attribution des bourses favorise l'entrée des enfants d'agriculteurs dans l'enseignement général, plutôt que dans l'enseignement agricole. Pour cela il faudrait raisonner à ressources égales et non à surface égale, et supposer que les parents aient conscience dlune disparité éventuelle. Toutefois, slil y avait disparité, linfluence de la surface en serait renforcée. 
Ces diverses observations relatives à des données de fait dictent quelques conclusions provisoires sur les mécanismes de llorientation des enfants d'agriculteurs vers l'enseignement agricole. Les élèves du cycle court, n'ont pas eu accès à l'enseignement général ou en sont sort is après la classe de 5è ; mais contrairement aux enfants scolarisés dans les classes pratiques de l'enseignement général (et sans doute aussi de ceux qui sont scolarisés dans l'enseignement technique), ils ont des parents installés sur de "grandes" exploitations. Contrairement aux élèves du cycle court agricole et des classespratiques, les élèves du cycle long agricole ont eu une réussite normale dans lienseignement général; mais à la différence des enfants qui ont pris la voie du second cycle général, ils sont issus, comme les élèves du cycle court agricole, de "grandes" exploitations. Ainsi les conditions d'offre d'emploi agricole et peut être aussi d'éventuelles disparités entre collège général et $C$. E. A. dans llattribution des bourses - tendent à donner à la dimension de l'exploitation des parents un rôle important dans l'orientation des enfants d'agriculteurs vers les deux cycles del'enseignement agricole.

L'opinion des élèves et des enseignants confirme-t-elle ces conclusions provisoires?

\section{Section $\|$ - ANALYSE DES OPINIONS DES ELEVES}

L'analyse des opinions des élèves relatives à l'orientation vers l'enseignement agricole s'appuie sur les réponses données à des questions ouvertes concernant à la fois les influences et les raisons qui ont guidé les choix. Beaucoup de ces "raisons" sont banales, les élèves interrogée nlayant pu eu suffisamment de temps pour réfléchir. Nous tiendrons compte par ailleurs desprojets scolaires des élèves du collège général.

Quelles influences ont pesé sur l'orientation vers l'enseignement agricole?

La question "qui vous a orienté vers l'enseignement agricole ?" a été posée à tous les élèves du C.E. A. . Les réponses font apparaître six types d'influence qui figurent au tableau suivant.

Chez les enfants d'agricul teurs du cycle court, ce sont lesparents et les éducateurs qui ont pesé le plus dans le "choix" de l'enseignement agricole : parents et instituteurs dans le cas des élèves provenant de l'école primaire, parents et professeurs ou directeur lorsque l'élève provient d'un C.E.G.. L'influence de ces instituteurs subsiste dans le second cas. Au niveau du cycle long, lintervention des parents et des enseignants diminue, les élèves ont plus souvent décidé eux-mêmesde leur orientation. L'auto-détermination est en particulier le fait de la 
moitié des élèves issus dlun premier cycle de type C.E.S..

Tableau n०10 - Influences ayant pesé sur le choix de l'enseignement agricole selon l'origine scolaire des élèves (enfants d'agriculteurs uniquement) en \%

\begin{tabular}{|c|c|c|c|c|}
\hline \multirow{2}{*}{\begin{tabular}{|l} 
Influences \\
Origine scolai- \\
re des enfants
\end{tabular}} & \multicolumn{2}{|c|}{$\begin{array}{c}\text { cycle court: } \\
\text { origine scolaire }\end{array}$} & \multicolumn{2}{|c|}{$\begin{array}{l}\text { cycle long: } \\
\text { origine scolaire }\end{array}$} \\
\hline & primaire & C.E.G. & C.E.G. & C.E.S. \\
\hline $\begin{array}{l}1 \text { - Instituteurs } \\
2 \text { - Directeurs, professeurs } \\
3 \text { - Parents } \\
4 \text { - L'élève (moi) }\end{array}$ & $\begin{array}{r}(30) \\
(4) \\
(48) \\
(18)\end{array}$ & $\begin{array}{l}(10) \\
(25) \\
(40) \\
(15)\end{array}$ & $\begin{array}{l}- \\
27 \\
32 \\
29\end{array}$ & $\begin{array}{l}- \\
(13) \\
(25) \\
(50)\end{array}$ \\
\hline $\begin{array}{l}5 \text { - Orientation scolaire et pro- } \\
\text { fessionnelle }\end{array}$ & - & $(10)$ & 6 & (6) \\
\hline $\begin{array}{l}6 \text { - Camarades } \\
\text { Autres }\end{array}$ & $\overline{-}$ & - & $\begin{array}{l}5 \\
1\end{array}$ & $\overline{(6)}$ \\
\hline $\begin{array}{l}\text { Total } \\
\text { Nombre de réponses }\end{array}$ & $\begin{array}{r}100 \\
24\end{array}$ & $\begin{array}{r}100 \\
20\end{array}$ & $\begin{array}{r}100 \\
61\end{array}$ & $\begin{array}{c}(100) \\
16\end{array}$ \\
\hline
\end{tabular}

Chez les élèves d'origine non agricole du cycle long, la hiérarchie des influences est particulière. Viennent en premier les "éducateurs" (près de la moitié des cas), puis les "élèves", les "parents" et "llorientation professionnelle"!.

Ainsi, d'une manière générale, cene sont pas tant les élèves que les parents et les éducateurs qui font le "choix", le rôle de llorientation scolaire étant tout à fait mineur. Ceci est à rapprocher des conclusions avancées par MM. REUCHLIN et BACHER à l lissue de leur importante étude (1). "Nous avons noté dlabord, avec l'expérience commune, la cohérence qui s'établit, à un niveau global d'observation, entrelesprojets des enfants, les projets des parents, les avis des professeurs et llorientation effective (2)". La cohérence entre les ambitions et les possibilités des enfants et de leur famille ne doit pas surprendre: "les unes et les autres sont liées, en effet, et de la façon la plus régulière, aux caractéristiques socio-économiques et culturelles de la famille, de l'enfant et de la région qu'il habite (3)". Ceci rejoint d'ailleurs les observations faites par A. GIRARD sur le niveau d'aspiration des familles. Et comment expliquer la cohérence globale constatée avec les avis des professeurs ? Ceux-ci ignorent en général l'origine sociale de l'élève mais ils la pressentent intuitivement, or un certain niveau de culture générale, un certain style de pensée et de langage (sans parler des possibilités matérielles) qui jouent un rôle important dans|lorientation s'ob-

(1) Llorientation à la fin du premier cycle secondaire, enquête de l'Institut National d'Orientation Professionnelle (I. N. O.P.)-Paris, PUF,1969.

(2) Idem, p. 85.

(3) Idem, P.82. 
servent plus souvent chez les enfants issus de milieux relativement favorisés. Enfin, selon MM. BOURDIEU et PASSERON (1), les enseignants agiraient le plus souvent, consciemment ou inconsciemment, dans le sens des mécanismes de sélection du système scolaire.

Ces régularités globales précisent MM. REUCHUN et BACHER, s'accompagnent d'importantes variations individuelles à l lintérieur d'un même milieu socio-économique. Les élèves étudiés intervenant peu dans le "choix'ble l'orientation, il convient d'examiner quelles "raisons" les élèves du C.E. A. donnent de leur orientation scolaire et de confronter ces réponses avec les raisons données par les élèves du collège général de leur non-entrée dans l'enseignement agricole. II sera ensuite interessant d'analyser quels jugements portent, ex-post, les élèves du $C$. E. A. sur leur orientation.

"Raisons" du choix ou du refus de l'enseignement agricole avancées par les élèves

Les élèves du C.E.A. étaient invités à répondre à la question suivante : "Pour quelles raisons y êtes-vous entréll ? Ceux du collège général ont eu à répondre à trois questions: "avez-vous pensé entrer dans l'enseignement agricole quand vous étiez en classe de $5 e$, 3e ?" "pourquoi n'êtes-vous pas entré dans l'enseignement agricole?" et"quels sont vos projets scolaires ?". Le dépouillement a permis de dégager des "réponses-type" dans chaque cas. Lorsque plusieurs réponses étaient avancées, nous n'avons retenu que les deux principales.

\section{- Elèves du C.E.A.}

Un tiers des réponses concerne le goût, l'intérêt pour l'agriculture, réponses souvent globales et banales du genre "llagricul ture $m$ 'intéresse", "j’aime çà" ... image intériorisée du devenir objectif ? Ensuite, la hiérarchie des réponses diffère selon le cycle suivi :

- cycle court :

$1-22 \%$ : Niveau insuffisant pour faire des études dans l'enseignement général,

$2-8 \%$ : Intérêt pour les matières enseignées.

$3-8 \%$ : Préparation à une profession,

$4-5 \%$ : Reprise d'une exploitation,

les cas 2) et 3) étant uniquement le fait des élèves d'origine non-agricole qui expriment leur intérêt pour les matières et leur désir d'avoir une formation professionnelle en vue d'un débouché rapide.

- cycle long :

1 - $16 \%$ : Intérêt pour les matières enseignées,

$2-14 \%$ : Origine agricole,

$3-12 \%$ : Préparation à une profession,

$4-10 \%$ : Réussite insuffisante dans l'enseignement général.

Les élèves de cycle court indiquent pour principale raison leurs mauvais résul tats scolaires dans l lenseignement général. Et ce sont les

(1) La reproduction, Paris, Ed. de Minuit, 1970. 
26.

élèves provenant de de la classe de $5^{\circ}$ qui le mentionnent le plus (46\% des réponses). L'un précise qu'il ne pouvait pas entrer au collège technique parce qu'il avait échoué à son examen d'entrée; notons qu'un tel examen n'existe pas dans le cycle agricole court.

$14 \%$ des élèves de cycle long justifient leur orientation par leur origine agricole, ce qui est peuexplicite. Est-ce la retraduction dlune mission spécifique confiée àl'enseignement agricole ? Relevons également que $10 \%$ des réponses reprennent l'explication de la relégation. Les élèves d'origine non agricole du cyclelong affirment principalement quand à ceux, qu'ils y sont venus par intérêt pour l'agriculture, les matières enseignées, et afin de se préparer à la vie professionnelle.

La nature des réponses suggère une remarque plus générale. La fréquence des cas où le "choix" de l'enseignement agricole n'est pas le fait de l'élève est à rapprocher de la fréquence des réponses où ce choix est pris à son propre compte par l'élève: est-ce que les élèves cherchent à justifier une décision souvent prise par dlautres en la réinterprêtant dlune manière personnelle? La fréquence des raisons banales exprimerait-elle la difficulté de prise à son compte de telles décisions?

\section{- El'èves du collège général}

Nous avons d'abord demandé aux élèves des classes de 4è et de 2 è slils s'étaient posés la question de l'orientation vers le C. E. A. avant leur entrée dans ces classes. Un seul élève a répondu affirmativement, un garçon dlorigine agricole. Par ailleurs, quatre élèves seulement projettent de rejoindre l'enseignement agricole. Ce sont tous des enfants dlagriculteurs. Il est donc exceptionnel que les élèves du collège général se sentent concernéspar llenseignement agricole; quelles sont les raisons de cette attitude ? Nous envisagerons successivement les réponses des enfants d'agriculteurs, puis celles des autres élèves.

La question "Pourquoi n'êtes-vous pas entré(e) dans l'enseignement agricolell a surpris un certain nombre d'enfants diagriculteurs. $12 \%$ dlentre eux ne se sont jamais posés la question. De plus, $38 \%$ des réponses sont du type "ça ne $m$ 'intéresse pas" - réponses banales, correspondant exact (mais inverse) de l'opinion des enfants d'agriculteurs du C.E.A. . Au-delà de cette indifférence relative, les raisons avancées concernent soit lesprojets scolaires, soit l lemploiagricole. Si, en section moderne courte, on affirme qu'on veut poursuivre des études générales jusqulau B.E.P.C., par contre, dans les sections longues, modernes ou classiques, on neprécise pas de cap. Plusieurs élèves disent qu'ils ne se sont pas orientés vers l'enseignement agricole parce qulils avaient obtenu des résultats scolaires satisfaisants. En ce qui concerne l'emploi, toutes les réponses ont pour objet le métier d'agriculteur, tantôt critiquant la pénibilité du travail, tantôt affirmant que clest un métier d'avenir incertain, tantôt expliquant que la succession des parents est déjà prise ou bien inintéressante parce que l'exploitation n'est pas "rentable". Cela rélève quelle finalité professionnelle est attribuée à l'enseignement agricole. Enfin, quelques-uns indiquent quils connaissent mal l'organisation de l'enseignement agricole.

Parmi les élèves d'origine non-agricole, la proportion de ceux qui ne se sont jamais "posés la question" n'est pasplus élevée. Mais les deux tiers des réponses sont banales ce qui exprime une indifférence plus 
grande que chez les élèves d'origine agricole. L'enseignement agricole semble encore perçu comme un enseignement professionnel, car $10 \%$ donnent comme raison leur origine non agricole. L'indifférence fait place à l'agressivité chez quelques élèves des classes pratiques: "Je n'en veux pas, c'est un métier sale", llenseignement agricole étant assimilé à la profession agricole.

On constate une certaine convergence des réponses selon quil s'agit d'élèves d'origine agricole ou non, en particulier chez les filles. L'indifférence est assez marquée. L'enseignement agricole est considéré comme un enseignement purement professionnel et destiné aux futurs agriculteurs. Ainsi le comportement des enfants dlagricul teurs du collège général se rapproche dans ce domaine de celui des autres élèves. Les réponses revèlent par ailleurs une mauvaise connaissance de cet enseignement et de ses débouchés, y compris chez les élèves du $C$. E.A. .

Les élèves du collège agricole sont-ils satisfaits de leur orientation scolaire et de la formation qu'ils reçoivent dans l'enseignement agricole?

Pour tenter de juger avec plus de recul l'orientation scolaire prise par les élèves du C.E.A., nous leur avons demandé si llenseignement agricole, sous sa forme actuelle, correspondait à ce quilis en attendaient et slils souhaiteraient faire les mêmes études au cas où celles-ci seraient à recommencer. Ce que les élèves attendent de l'enseignement agricole est en rapport avec les raisons pour lesquelles ils sont venus vers ce type de scolarité. L'examen des réponses aux questions posées (tableaux $n^{\circ} 11-12$ ) permettra donc de mieux connaître les déterminants de l'orientation vers la formation agricole en même temps qulil fera apparaître comment les élèves assument un "choix" qui n'a pas été le leur en général.

Tableau n¹1 - Réponses à la question: "Si vos études étaient à recommencer, souhaiteriez-vous faire la même chose ?"

(en $\%$ )

\begin{tabular}{|c|c|c|c|c|}
\hline \multirow{2}{*}{ réponses } & \multirow[b]{2}{*}{$\begin{array}{l}\text { collège } \\
\text { général }\end{array}$} & \multicolumn{2}{|c|}{ C. E. A. } & \multirow[b]{2}{*}{ ensemble } \\
\hline & & $\begin{array}{l}\text { cycle } \\
\text { court }\end{array}$ & $\begin{array}{c}\text { cycle } \\
\text { long }\end{array}$ & \\
\hline Oui & 45 & 43 & 38 & 40 \\
\hline Non & 14 & 31 & 38 & 35 \\
\hline Ne sait pas & 41 & 26 & 24 & 25 \\
\hline Total & 100 & 100 & 100 & 100 \\
\hline
\end{tabular}


28.

Tableau $n^{\circ} 12$ - L'enseignement agricole sous sa forme actuelle correspond-il à ce qu'en at tendentles élèves du C.E.A. (en \%)

\begin{tabular}{|l|c|c|}
\hline Réponses & Cycle court & Cycle long \\
\hline Oui & 25 & 10 \\
Non & 8 & 14 \\
En partie & 61 & 64 \\
Nesaitpas & 6 & 12 \\
Total & 100 & 100 \\
\hline
\end{tabular}

Les réponses à la première question sont trois fois plus souvent négatives chez les élèves du collège agricole que chezles élèves du collège général. Le rapport est le même pour les seules élèves d'origine agricole. Mais ce qui est regretté le plus souvent n'est pas l'orientation vers l'enseignement agricole. Les causes de l'insatisfaction sont de divers ordres et varient en particulier selonle niveau de formation agricole.

\section{- Elèves du cycle court}

Cinq élèves auraient préféré poursuivre leurs études dans l'enseignement général, soit par refus de l'enseignement agricole, soit pour avoir une culture générale plus complète avant de s'y orienter? trois auräient aimé entrer dans une école technique; et cinq regrettent de ne pas être passés directement de la classe de 6è du cycle d'observation (enseignement général) à la classe du 4 è du cycle court agricole, ce qui leur aurait permis de gagner une ou plusieurs années! Ces divers élèves proviennent de l'enseignement général et seule une minorité d'entre eux a accepté la relégation dans le cycle court.

S'agissant de l'appréciation de la formation reçue dans l'enseignement agricole, presque tous les commentaires donnés par les élèves de cycle court expriment la revendication d'un enseignement strictement professionnel, tant au titre du contenu des programmes qulen ce qui concerne la pédagogie. Clest l'insuffisance du nombre d'heures de cours d'agriculture qui est laplus décriée. Ensuite, on réclame davantage de zootechnique, de biologie, au détriment du français et des mathématiques. Cependant, l'aspiration à un enseignement proprement appl iqué est avant tout le fait des élèves de la classe de seconde, celle qui prépare à l'examen du B. A. A.. On considère par ailleurs dans toutes les classes que les travaux pratiques de ferme devraient être supprimés, ou réservés à ceux qui ne sont pas "du milieu" (ceux-ci en demandent davantage). II est significatif quion aille jusqu'à proposer des aménagements visant à permettre aux enfants dlagriculteurs de faire des "T.P. de ferme" chez eux. Ainsi, leur passéscolaireles incite à rejeter les valeurs scolaires au bénéfice des valeurs familiales. Comme leurs parents, ils accordent une place prépondérante au savoir faire. L'utilité détermine liintérêt. Cette attitude rappelle celle qu'analyse CL. GRIGNON chez les élèves de C.E.T. (1).

(1) C. CRIGNON, Approntissage d'un métier ou acquisition de la colulture: les apprentis à l'école. Communication faite au Congrès Mondial de Sociologie d'Evian (5-12 Sept. 1966); document ronéoté. 
- Elèves du cycle long

Le problème de l'orientation et des aspirations de formation est plus compliqué chez les élèves du cycle long. Chaque élève a été invité à répondre à deux questions complémentaires :

- A ceux qui proviennent de I'ancien llè cycle agricole, nous avons demandé:

- d'une part, s'ils avaient rencontré des difficul tés d'ordre scolaire en passant dans le cycle long (si oui, lesquelles ?)

- d'autre part, s'ils auraient préféré suivre l'enseignement général jusqu'en classe de 3è (pourquoi ?).

- Ceux qui viennent de la classe de 3è de l'enseignement général ont eu à répondre à deux questions :

- "Pensez-vous qu'il aurait mieux valu que vous suiviez l'enseignement agricole dès la classe de 4èll (pourquoi ?)

- "Auriez-vous préféré poursuivre vos études dans l'enseignement général plutôt que rejoindre le cycle long agricolell (pourquoi ?).

Sur 24 élèves provenant de l'ancien second cycle, 14 déclarent avoir rencontré des difficultés - souvent sérieuses - en mathématiques et en anglais. Mais parmi ces 14 élèves, la moitié seulement aurait préféré suivre l'enseignement général jusqulen $3 \mathrm{e}$, les autres expliquant que l'agricul ture les intéresse beaucoup, ou bien qu'ils ont gagné un an en suivant la filière : 6è générale - 4è, 3è agricole court, 2è agricole long ! En tout cas, on peut supposer que, désormais, il sera très difficile à un élève du cycle court de rejoindre le cycle long.

Peu d'élèves du cycle long considèrent qu'il vaut mieux suivre l'enseignement agricole à partir de la classe de 4è plutôt qulà partir de la classe de seconde. Llexplication suivante est représentative des raisons de cette position : "Je ne pense pas qulil vaille mieux suivre l'enseignement agricole dès la 4e, car l'enseignement général n'y est pas assez poussé et l'on risque d'être handicapé par la suite. De plus, on n'est pas encore sûr du métier qu'on exercera dans l'avenir'l. En outre, cela permet d'ayoir au moins le B.E.P.C. dont plusieurs estiment, à tort ou à raison, 'i va valeur est nettement supérieure à celle d'un $B$. A. A. ou d'un B.P.A. .

Les élèves de cycle long auraient-ils préféré suivre l'enseignement général jusqulaubaccalauréat ? Lamajorité des réponses sont négatives: dans l'ensemble on ne regrette pas d'avoir un enseignement moins abstrait et plus spécifique. Mais en classe de seconde, près de la moitié des élèves hésitants se résigne avec peine de ne pas être assez "doués" pour des études générales. Surtout, la moitié des élèves de terminale B.T. A. et tous les élèves de terminale DI auraient préféré rester dans l'enseignement général.

Cette opposition entre ceux qui acceptent le cycle long agricole et ceux qui regrettent le second cycle général se retrouve en partie quand il s'agit d'apprécier la formation dispensée dans l'enseignement agricole. Pour les premiers, les solutions proposées ne consistent pas tant à modifier le contenu des programmes - comme clétait le cas dans le cycle court - qu'à changer les méthodespédagogiques: "trop de théorie, il faudrait une place égale à la théorie et à la pratique". 
30.

Par contre, la totalité de la section terminale $D^{\prime}$ et une dizaine d'autres élèves, pour laplupart en section terminale B. T. A., revendiquent une formation plus générale. Pour les élèves de B. T. A., il s'agit de sortir dlune filière qui restreint les études supérieures à la préparation du B.T.S.A., ou tout aumoins qui interdit defaire des études supérieures longues.

En résumé, si la majorité des élèves de l'enseignement agricole accepte expréssement ce type d'enseignement, une forte minorité, spécialement dans le cycle long, le refuse et aspire à une formation plus générale. De la part de ces derniers, l'orientation vers une scolarité agricole est-elle la sanction d'une auto-sélection dictée par les risques qulinspire le baccalauréat de l'enseignement général ?

Une telle proportion de refus n'a pas surpris les enseignants. Ceux-ci nous ont donné leur point de vue sur l'ensemble des informations précédentes. Ils nous ont également décrit l'évolution du recrutement dont ils ont été les témoins depuis une dizaine d'années.

\section{Section III - LE POINT DE VUE DES ENSEIGNANTS}

Certains enseignants ont été surpris de constater que les élèves du collège général manifestaient peu d'animosité à l'égard de l'enseignement agricole. Autrefois, il existait une tension très vive entre les élèves du collège général et ceux du C.E. A. . Les premiers considéraient les seconds comme des "bouseux" et ceux qui s'aventuraient seuls dans le camp "adverse" devaient savoir qulils couraient des risques. Depuis cinq à dix ans, ces tensions se sont largement atténuées - sans doute corrélativement à l 'extension du recrutement du collège général en milieu rural. Néanmoins, pour unélève du "général" clest un peu déchoir que d'aller dans l'llagricole". Le site des deuxécoles traduit cet état de choses : le C.E.G., situé en hauteur, est orienté vers la ville et la cathédrale (témoin de cul ture et fierté des habitants), alors que le C.E.A., installé en contre-bas, ouvre la perspective des prés et du travail des champs.

Comme $22 \%$ seulement des élèves du cycle court expliquent leur orientation vers l'enseignement agricole par la médiocrité de leurs résultats scolaires, les enseignants estiment qu'ils sont "moins complexés qu'on aurait pu le penser".

Cette perception del'attitude des élèves est liée chez les enseignants à leur opinion sur les déterminants de llorientation vers l'enseignement agricole. 
Opinion sur les raisons d'entrée au collège agricole

La majorité des élèves du cycle court agricole y entrerait parce que, dlune part, leurs parents ont une "exploitation viable" et sont confiants dans l'avenir de l'agriculture,et que, d'autre part, ces élèves ne sont pas aptes à faire des études générales ou agricoles longues.

En ce qui concerne le cycle long, une bonne partie des élèves aurait pu réussir des études générales longues. Cependant, pour les parents, le baccalauréat c'est "tout un monde" et ce serait faire preuve de témérité que d'essayer de l'atteindre. En outre, "que ferait-il avec son bac"l? Par contre, ils voient déjà leur fils dans le rôle de tous ces "messieurs en cravate et veston" qui viennent les conseiller ou qui travaillent dans les bureaux des organismespara-agricoles. Clest quelque chose de concret qui peut être atteint en trois ans avec, semble-t-il, beaucoup plus de chances. Ou alors, le fils sera un chef d'entreprise compétent à la tête dlune "grosse" exploitation.

Compte tenu du rôle ainsi exercé par de tels projets professionnels, la zone rurale qui environne le C.E. A. n'est pas une aire propice à l'orientation des enfants d'agricul teurs versl'enseignement agricole. Les perspectives d'emploi agricole y sont peu favorables car llagricul ture y est peu organisée et peu dynamique. Ceci apparaît au regard de critères tels que le nombre de coopératives dlutilisation du matériel agricole, le nombre d'adhésions au Centre de Gestion ou d'inscriptions au Contrôle Laitier.

II s'y ajoute l'influence défavorable d'une perte de confiance des agriculteurs dans leur profession remarquée depuis quelques années par certains enseignants.

Certains élèves d'origine non agricole rejoindraient le C.E. A. par relégation, leur environnement social ayant des affinités avec liagriculture (oncle agriculteur, possession de fermes, ami technicien agricole ...). Le directeur duC.E. A. est parfois surprispar les raisons qui poussent certains parents à inscrire leur élève au C.E. A. : elles relèvent d'une perception spéciale de l'agriculture. Par exemple une femme d'architecte explique avec conviction que son fils aime la nature, les pigeons (il en élève dans une cage), le cheval (il aime les courses de chevaux ....). Notons que clest la femmequi avait fait la démarche. Elle conjurait en quel que sorte la relégation de son fils par la production d'un discours magico-esthétique.

Evolution du nombre et du niveau des candidats à la formation agricole

A l'époque de la mise en place de la réforme de l'enseignement agricole dlaoût 1960 , les parents acceptaient difficilement de scolariser leur fils dans l'enseignement secondaire et cet te réticence se manifestait également à l'égard de l'enseignement agricole. Clétaitl'époque de l'enseignement missionnaire : "il fallait parfois passer des heures à convaincre les parents, passer en revue tous les arguments, retourner les voir plusieurs fois ... c'était presque un enlèvement !"

Ceci rejoint les observations de CL. GRIGNON (1) sur la réti(1) $\mathrm{Cl}$. GRIGNON, L'orientation scolaire des élèves dans une commune rurale, Revue Française de Sociologie IX, nº spécial 1968, pp. 218226, pages 220 et 221 . 
cence d'une société rurale traditionnelle vis à vis de la poursuite des études. Les parents interrogés "soul ignent le caractère anormal qu'eût comporté pareille option à leur époque, et l a réprobation qulelle eût suscitée de la part de la collectivitél". Pour que des parents "se résolvent à envisager l'entrée d'un enfant au collège, il faut que l'Ecole fasse les premier pas ; les démarches répétées de l'instituteur auprès des parents, la promesse d'une bourse sont despréalables indispensables car ils manifestent l'intérêt que l'école porte à l'élève et témoignent ainsi de sa valeur que les parents ne peuvent mesurer eux-mêmes, et qui est le gage de la réussite ul térieure".

Dans notre exemple, les pionniers ont été de plus en plus imités les années suivantes. Clest également la phase de développement des C.E.G.. Durant toute cette période, les élèves recrutés par le collège agricole ont un niveau scolaire assezélevé, quel que soit le cycle. Depuis deux ou trois années, par contre, on observe un abaissement du niveau des candidats au cycle court.

$\therefore$

Opinions et données de fait convergent pour faire apparaître que l'orientation vers l'enseignement agricole résulte de l'action - tantôt séparée, tantôt conjointe - de deux groupes de facteurs, les uns liés à la réussite scolaire, les autres relatifs aux projets professionnels.

Actuellement, mais il n'en a pas toujours été ainsi, entrent dans le cycle court des enfants qui n'ont pas réussi à poursuivre des études dans l'enseignement général; ils ont liintention de reprendre l lexploitation, relativement grande - de leurs parents. L'orientation des élèves de cycle long obéit à la double influence de l'intérêt pour l'agriculture et de la crainte de l'échec suscitéepar les formes abstraites de la culture générale conduisant au baccal auréat ; la reprise dlune exploitation semble être un motif secondaire d'orientation vers le cycle long. L'appréciation plus ou moins consciente des chances objectives d'accéder à tel type de scolarité semble déterminer le niveau d'aspirationdlun certain nombre d'élèves, et infléchir jusqulà leurs "goûts".

L'enseignement agricole est généralement perçu comme un enseignement à finalité professionnelle à la fois par les parents, les enseignants et les enfants, que ceux-ci soient élèves dans le général ou dans llagricole. Il est considéré comme une préparation au métier d'agriculteur, ou, mieux encore, selon une hiérarchie des valeurs professionnelles appréciées de certains parents, auxmétiers non manuels duparaagricole - quand les résultats scolaires l'autorisent.

Compte tenu des résultats scolaires obtenus par les enfants soit dans le primaire, soit dans le ler cycle de l'enseignement général, compte tenu aussi des perspectives de placement que laissent entrevoir la situation économique de l'exploitation desparents et le diplôme recherché, lịnvestissement en éducation agricole, courte ou longue, serait bien le plus rentable pour ceux qui le choisissent. Clest celui qui comporte le moins de risques d'échec scolaire et d'échec de placement. La liaison entre nature et niveau de formation et choix professionnels serait ainsi 
33.

très stricte dans le cas de l'enseignement agricole. L'analyse des choix professionnels déclarés par les élèves montre-t-elle qulil en est bien ainsi ? 
35.

Chapitre III -

LES PROJETS PROFESSIONNELS COMPARES DES ELEVES

DE L'ENSEIGNEMENT AGRICOLE ET DES ELEVES DE

L'ENSEIGNEMENT SECONDAIRE

Les projets professionnels déclarés par les élèves des deux types d'enseignement ont été examinés sous l'angle de la liaison entre formation secondaire générale ou agricole à temps plein et entrée dans l'agriculture. Pour le collège agricole, nous avons cherché s'il existait une relation entre le niveau d'instruction atteint et les choix respectifs de l'agricul ture et des secteurs para-agricoles. Sillentrée dansl'agriculture ou dans les carrières para-agricoles étaitle but poursuivi lors de l'orientation vers l'enseignement agricole, elle n'en est pas forcément le résultat car les projets professionnels peuvent toujours être remis en cause.

II a été reproché parfois àl'enseignement agricole de trop orienter vers l'agriculture. Nous avons observé dans l'enquête générale d'llle-et-Vilaine que la majorité des titulaires dlune formation agricole s'orientent vers l'agriculture quand leurs parents ont une "grande" exploitation. Mais cette enquête étudiait essentiellement l'enseignement agricole à temps partiel. Qu'en est-il de l'enseignement à temps plein, court ou long ? On peut se demander si, comme l la voulu la loi d'août 1960, cet enseignement est autant un moyen de quitter l'agriculture que de s'y préparer. Une comparaison avec l,'enseignement secondaire général fera mieux apparaître la spécificté de l'enseignement agricole.

Après avoir indiqué comment les projets d'entrée dans l'agriculture varient selon la nature et le niveau de la formation, nous examinerons les explications des projets d'entrée et de non-entrée telles qulelles sont indiquées par les élèves. Notons que les projets professionnels des plus jeunes peuvent êtreprovisoires ou même parfois fantaisistes. 
36.

Section 1 - LES PROJETS DIENTREE DANS L'AGRICULTURESELON LA NATURE ET LE NIVEAU DE LA FORMATION ENCOURS

Les tendances observées lors de l'enquête générale d'llle-et-Vilaine dans les liaisons entre formation reçue et emplois effectivement exercés se retrouvent-elles dans l'étude monographique ?

Opposition entre formationgénérale et formation agricole (tableau n¹3)

Comme le laissait prévoir leur attitude vis-à-vis de l'enseignement agricole, les élèves dlorigine agricole de l'enseignement généralse détournent massivement de l'agriculture. Seulement $7 \%$ des garçons et $5 \%$ des filles projettent d'être agriculteurs ; certains entreront ultérieurement dans l'enseignement agricole. Le projet d'être agriculteur est encore plus exceptionnel (un seul cas) chez les élèves d'origine non agricole du collège général. Ainsi dans l'enseignement général l'attitude des enfants d'agriculteurs rejoint beaucoup celle des autres enfants comme on l'a déjà constaté à propos de l'orientation scolaire.

Tableau n॰13 - Projets d'entrée dans llagriculture selon la formation suivie

\begin{tabular}{|c|c|c|c|c|c|c|c|c|c|c|}
\hline \multirow{3}{*}{ projets $\quad \begin{array}{c}\text { formation } \\
\text { suivie }\end{array}$} & \multicolumn{4}{|c|}{ Collège général } & \multicolumn{6}{|c|}{ C.E.A. (garçons) } \\
\hline & \multicolumn{2}{|c|}{ Filles } & \multicolumn{2}{|c|}{ Garçons } & \multicolumn{2}{|c|}{$\begin{array}{l}\text { cycle } \\
\text { court }\end{array}$} & \multicolumn{2}{|c|}{$\begin{array}{l}\text { cycle } \\
\text { long }\end{array}$} & \multicolumn{2}{|c|}{ ensemble } \\
\hline & nbre & $\%$ & nbre & $\overline{\%}$ & nbre & $\%$ & nbre & $\%$ & nbre & $\bar{q}_{0}$ \\
\hline$\frac{\text { Enfants d'origine }}{\text { agricole }}$ & & & & & & & & & & \\
\hline Entrée & 3 & 5 & 3 & 7 & 28 & 80 & 21 & 32 & 49 & 49 \\
\hline Non-entrée & 52 & 85 & 34 & 83 & 5 & 14 & 33 & 51 & 38 & 38 \\
\hline Ne sait pas & 6 & 10 & 4 & 10 & 2 & 6 & 11 & 17 & 13 & 13 \\
\hline Total & 61 & 100 & 41 & 100 & 35 & 100 & 65 & 100 & 100 & 100 \\
\hline $\begin{array}{l}\text { Enfants d'origine non- } \\
\text { agricole }\end{array}$ & & & & & & & & & & \\
\hline Entrée & 1 & 1 & - & _ & - & & - & & - & \\
\hline Non-entrée & 81 & 98 & 68 & 92 & 2 & & 11 & & 13 & \\
\hline Ne sait pas & 1 & 1 & 6 & 8 & - & & - & & - & \\
\hline Total & 83 & 100 & 74 & 100 & 2 & & 11 & & 13 & \\
\hline
\end{tabular}

Si $80 \%$ des élèves d'origine agricole du cycle court prévoient d'être agricul teurs (1) et (2), par contre, au niveau ducycle long, cette proportion slabaisse à $32 \%$ et l'examen des chiffres section par section revèle une diminution régul ière au fur et à mesure que le niveau de formation s'élève : $50 \%$ d'llentréell en section B.T.A.O., $28 \%$ en section B. T.A. et moins encore en section DI.

(1) à l'exclusion des horticulteurs, maraîchers, pépiniéristes.

(2) Notons que pour obtenir un prêt d'installation de jeune agriculteur il faut justifier de la possession du B.A.A. ou de cinq années d'exercice de la profession agricole. 
L'influence du niveau de formation agricole sur l'entrée dans l'agriculture est donc très forte. Elle apparaît encore plus nettement si llon établit la relation entreles projets d'entrée et le niveau de formation souhaité. Quant on passe du niveau B. A. A. au niveau B. T.S. A. , le taux d'entrée diminue régul ièrement de $96,5 \%$ à $21 \%$, le taux dé non-entrée s'élevant de $3,5 \%$ à $63 \%$. Ces pourcentages montrent également que l'indécision est plus grande aux niveaux de formation plus élevés.

Si les enfants d'agriculteurs scolarisés dans le cycle long agricole se détournent souvent de l'agriculture, si, parailleurs, les élèves d'origine non agricole du collège agricole n'envisagent jamais d'entrer dans l'agriculture, dans l'un et l'autre cas clest pour se diriger, en partie, vers les emplois para-agricoles. Nous considérons comme paraagricoles les secteurs qui ont pour activitéprincipale llachat ou la vente de biens ou de services au secteur agricole (1).

Aux élèves qui avaient déclaré ne pas vouloir êtréagriculteurs, il était demandé quel métier ils désiraient exercer. Le classement des métiers ne permet pas de passer àla nomenclature des secteurs. Aussi avons-nous seulement isolé les cas où les métiers déclarés relevaient explicitement du para-agricole, pour constituer une rubrique "professions des secteurs para-agricoles" (tableau n०14): Une rubrique spéciale a également été prévue pourles horticulteurs, maraîchers, pépiniéristes.

Pas un seul élève du cycle court n'envisage d'avoir un emploi dans le para-agricole. Les professions d'horticulteur, maraîcher, pépiniériste ne sont envisagées que par des élèves de ce cycle.

Dans le cycle long, par contre, la moitié des élèves d'origine agricole qui n'entreront pas dans l'agriculture, projette d'exercer une profession para-agricole, de même que la moitié des élèves d'origine non agricole.

Aucun élève de l'enseignement général ne se prononce pour les secteurs para-agricoles. Cette fois encore, ces élèves ne se différencient pas en fonction de l'origine sociale, agricole ou non.

II est intéressant de remarquer que, si presque tous les futurs agriculteurs avaient formé ce projet professionnel avant d'entrer dans l'enseignement agricole, - parfois dès leur enfance - par contre, la majorité de ceux qui envisagent desprofessions para-agricoles se sont déterminés depuis leur entrée dans cet enseignement. On inverserait l'enchaînement"des choix"en affirmant, par exemple, que le cycle court oriente vers l'agriculture. On peut donc dire, en tenant comp te des données de l'enquête statistique d'llle-et-Vilaine, que les futurs agriculteurs de la région ne ressentent pas le besoin dlune formation d'un niveau supérieur à celui du cycle court agricole (saufexception); en conséquence, le cycle long se trouve peuplé d'élèves qui y sont venus tantôt pour se préparer à un métier précis, tantôt: en pensant y recevoir un enseignement mieux adapté, à leur portée, sansprojet professionneldidé-

(1) Cf. F. PETIT et A. BRUN, Note sur l'évolution de la population active agricole et para-agricole, I.N.R.A. Station Centrale d'Economie et de Sociologie Rurales, juin 1967, ronéo, p.4. 
38.

Tableau n०14 - L'orientation des garçons vers les professions para-agricoles en fonction de la formation et de llorigine sociale

\begin{tabular}{|c|c|c|c|c|c|c|}
\hline \multirow[b]{2}{*}{$\begin{array}{l}\text { Professions } \\
\text { envisagées }\end{array}$} & \multicolumn{4}{|c|}{ C.E.A. } & \multicolumn{2}{|c|}{ Collège général } \\
\hline & $\begin{array}{l}\frac{d}{0} \\
\frac{5}{6} \\
\frac{0}{2} \\
\frac{1}{2} \\
0 \\
\pi\end{array}$ & 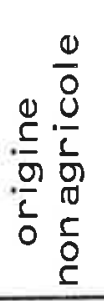 & 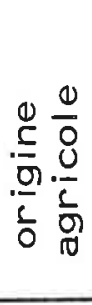 & 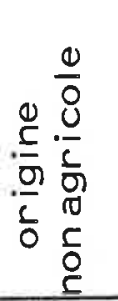 & $\frac{0}{\frac{0}{0}} \frac{0}{0}$ & 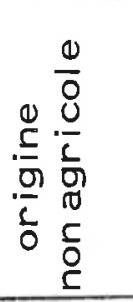 \\
\hline $\begin{array}{l}\text { Professions des secteurs } \\
\text { para-agricoles }\end{array}$ & - & - & 16 & 5 & - & - \\
\hline $\begin{array}{l}\text { Horticulteurs, maraîchers, } \\
\text { pépiniéristes }\end{array}$ & 1 & 2 & - & - & - & - \\
\hline Autres & 4 & 1 & 6 & 5 & 23 & 61 \\
\hline Ne se prononcent pas & - & - & 9 & 1 & 5 & 7 \\
\hline Total & 5 & 3 & 31 & 11 & 28 & 68 \\
\hline
\end{tabular}

A l'exclusion des cas non précisés

Si les projets professionnels des élèves dlorigine agricole du collège agricole varient selon les niveaux de formation pour chacun de ces niveaux ils peuvent être influencés par la dimension de l'exploitation des parents.

Les projets des élèves au collège agricole selon la dimension de l'exploitation de leurs parents

Dans l'enquête générale d'llle-et-Vilaine, les taux de maintien dans l'agriculture des titulaires dlune formation agricole cour te augmentent significativement avec la surface de llexploitation des parents. De même, dans une enquête faite en Suède en 1950-1951 sur les intentions professionnelles des élèves des écoles d'agriculture (niveau non précisé), il était apparu que l'exercice d'un emploi agricole était d'autant plus souvent envisagé que la surface de l'exploitation des parents était plus grande (1).

Dans la présente monographie, la superficie moyenne des parents est plus élevée chez les futurs agricul teurs du cycle court que chez l'ensemble des élèves de ce cycle. Mais on sait que la plupart des élèves de l'agricole court forment le projet d'être agriculteur.

(1) Enquête citée par C.E. BISHOP, La mobilité géographique et professionnelle de la main-d'oeuvre rurale, O.C.D.E., 1965, p. 23-24. 
Dans le cycle long, la concurrence apparaît vive entre le choix de la reprise dlune exploitation et le choix dlune "situation" non agricole que laisse entrevoir le diplôme espéré. Le tableau suivant montre comment s'exerce, dans de cycle, l'influence de la taille de l'exploitation des parents, telle qulelle est saisie par la surface et la présence de productions spécial isées.

Tableau n॰15 - Influence de la surface et des productions spécialisées sur l'entrée dans l'agriculture au niveau du cycle long

\begin{tabular}{|l|c|c|}
\hline \multicolumn{1}{|c|}{ Classe de surface } & $\begin{array}{c}\text { Tauxd'entrée } \\
\text { (projets) }\end{array}$ & $\begin{array}{c}\text { Rôle des productions spé- } \\
\text { cial isées }\end{array}$ \\
\hline S.A.U. < 15 ha & $10 \%$ & négligeable \\
\hline 15 hasS.A.U. $<30$ ha & $26 \%$ & $\begin{array}{l}\text { leur présence fait varier du } \\
\text { simple au double le taux } \\
\text { d'entrée }\end{array}$ \\
\hline S.A.U. $\geqslant 30$ ha & $50 \%$ & négl igeable \\
\hline
\end{tabular}

Le taux d'entrée s'élève nettement avec la dimension. Sur les petites et grandes exploitations, le choix de l'entrée semble indépendant de la présence de productions spécial isées, car la surface y est, ou trop faible, ou trop grande pour que celles-ci puissent jouer un rôle important. Par contre, entre 15 et 30 ha le taux d'entrée varie du simple au double selon la présence ou l'absence de productions spécialisées.

Plus le niveau de formation atteint s'élève, plus s'accroît le manque à gagner qui résulte de la reprise dlune exploitation agricole par rapport à l'adoption d'un emploi de cadre moyen, sauf si la dimension de l'exploitation à reprendre est trèsélevée. II reste à donner un contenu à cette expression de "manque à gagner" : s'agit-il des conditions de travail, du niveau de vie, ou d'autres éléments ? Clest ce que nous allons essayer d'approfondir au travers des déclarations des élèves qui projettent ou non d'entrer dans l'agriculture.

\section{Section $\|$ - LES EXPLICATIONS DONNEES PAR LES ELEVES DE LEURS PROJETS DIENTREE OU DE NON-ENTREE}

Les raisonnements précédents confèrent implicitement une place privilégiée, dans l'orientation professionnelle, au revenu qui est attendu soit dlun diplôme ayant un certainprixsurle marché du travail, soit de la reprise d'une exploitation de dimension donnée. Est-ce justifié,compte 
40.

tenu des réponses données par les élèves aux questions suivantes : - pour ceux qui projettent d'entrer dans llagriculture et pour ceux qui hésitent : pourquoi ?

- pour les autres : "si vous ne voulez pas être agriculteurs, pouvezvous indiquer les raisons précises ?"

Cette fois encore, nous avons recueilli beaucoup de réponses banales. Le dépouillement a permis de faire apparaître des réponses types Examinons successivement les raisons de l'entrée, celles de la non-entrée et les interrogations de ceux qui hésitent.

\section{Raisons de l'entrée}

Les raisons les plus précises avancées par les élèves de cycle court se réfèrent, par ordre de fréquence décroissant, aux arguments suivants :

- une succession intéressante à prendre

- la liberté de l'agriculteur

- le fait de ne pas pouvoir faire autre chose

- le fait d'être d'origine agricole

On retrouve des arguments semblables au niveau du cycle long mais les raisons exprimées sont plus variées et surtout se réfèrent plus souvent à des contraintes familiales, par exemple la nécessité "dlaider à la ferme pour permettre aux frères et soeurs de faire des études eux aussi".

Vis à vis du statut social de l'agriculteur les points de vue sont assez contrastés. Quelques-uns choisissent ce métier parcequils pensent "qulà llavenir il sera un des métiers à conserver le sens de la responsabilité de l'homme", et considèrent qulil nécessite de larges capacités, beaucoup de connaissances. Mais les entrants ont plus fréquemment le sentiment que clest une profession un peu déconsidérée ; llun tient à souligner que "clest un métier comme les autres", un autre le choisit parce quill ne peut pas "poursuivre" assez loin ses études.

Ainsi, peu d'élèves semblent vraiment conscients de la difficul té que constitue la conduite diune exploitation agricole.

Le projet d'entrée dans l'agriculture semble résulter d'un compromis entre les possibilités de reprise et les avantages et inconvénients de cette profession, perçus principalement en termes de condition sociale (liberté, dévalorisation), compromis qui se déplace en faveur des professions para-agricoles lorsque le niveau scolaire s'élève; quelles sont les raisons déclarées du choix de la non-entrée ?

\section{Raisons de la non-entrée}

Les réponses types ont été regroupées de la façon suivante pour faciliter llinterprétation. 
Tableau n¹6 - Raisons types de la non-entrée dans l'agricul ture déclarées par les élèves (en \%)

\begin{tabular}{|c|c|c|c|c|c|}
\hline $\begin{array}{l}\text { Origine sociale, } \\
\text { sexe, établisse }\end{array}$ & Origi & ine agric & ole & $\begin{array}{r}\text { Origine } n \\
\mathrm{col}\end{array}$ & hon agri- \\
\hline "raisons-types" & C.E. A. & $\begin{array}{l}\text { çons } \\
\text { collège } \\
\text { général }\end{array}$ & $\begin{array}{l}\text { filles du } \\
\text { collège } \\
\text { générạl }\end{array}$ & \begin{tabular}{|c|} 
garçons \\
du collè-- \\
ge géné- \\
ral
\end{tabular} & $\begin{array}{l}\text { filles du } \\
\text { collège } \\
\text { général }\end{array}$ \\
\hline $\begin{array}{l}\text { Le manque de goat et } \\
\text { d'intérêt pour l'agri- } \\
\text { culture }\end{array}$ & 17 & 17 & 51 & 57 & 64 \\
\hline $\begin{array}{l}\text { Les difficul tés d'ins- } \\
\text { tallation }\end{array}$ & 30 & 27 & - & 3,5 & 2,5 \\
\hline $\begin{array}{l}\text { L'insuffisance ou la } \\
\text { variabilité du revenu }\end{array}$ & 28 & 23 & 5 & 3,5 & - \\
\hline $\begin{array}{l}\text { La dureté, la pénibilit } \\
\text { du travail }\end{array}$ & 6 & 23 & 23 & 13 & 12,5 \\
\hline $\begin{array}{l}\text { Le caractère astrei- } \\
\text { gnant du travail (pas } \\
\text { de week-end, pas de } \\
\text { vacances) }\end{array}$ & 19 & 10 & 21 & 11,5 & 6 \\
\hline L'origine non-agricole & - & - & - & 11,5 & 15 \\
\hline Total & 100 & 100 & 100 & 100 & 100 \\
\hline
\end{tabular}

Ce mode de regroupement permet diidentifierdlune part deux ensembles d'élèves ayant un comportement semblable : les garçons dlorigine agricole (quel que soit l'établissement), les élèves d'origine non agricole du collège général (quel que soit le sexe), et dlautre part un groupe d'élèves ayant un comportement intermédiaire, celui des filles d'origine agricole du collège général. Clest chez les premiers que les réponses sont le moins souvent banales.

Qu'ils soient au C.E. A. ou au collège général, les garçons d'origine agricole ne se détournent pas tant de l'agricul ture par manque de goût et d'intérêt, que sous l'action de trois contraintes qui revêtent une importance analogue dans leurs déclarations :

- l'insuffisance et la variabilité du revenu,

- les difficultés diinstallation,

- les caractères pénible et astreignant du travail.

Les difficultés d'installation rendent compte avant tout de l'étroitesse des structures et de l'ampleur des investissements à réaliser.

Les garçons et filles d'origine non-agricole affirment principalement que llagriculture ne leur plaît pas ou ne les intéresse pas. Ils ne semblent conscients ni des difficultés diinstallation, ni des problèmes de revenus, mais ils sont sensibles à la dureté du travail (à un degré 
moindre chez les filles) et à son caractère astreignant. Ils invoquent également le fait qu'ils ne sont pas d'origine agricole. Les garçons d'origine non-agricole du C.E. A. ne figurent pas sur le tableau à cause du petit nombre de réponses; leur comportement ne se distingue que sur un point de celui qui vient d'être décrit : ils sont plus conscients des difficultés diinstallation et de revenu - sans doute par le contact quilis ont avec les enfants d'agriculteurs etl'agriculture. En somme, pour les élèves diorigine non agricole, la question ne se pose pas tant le statut de la profession agricole leur semble particulier et dévalué.

Les filles d'origine agricole du collège général insistent autant sinon plus que les garçons diorigine agricole sur les conditions de travail. Par contre, elles ne mentionnent pas davantage les problèmes dinstallation et de revenu que les filles d'origine non agricole du collège général. Comme ces dernières, elles donnent d'emblée la réponse banale selon laquelle llagricul ture "neleurplaît pas". Cette opposition d'attitude entre garçons et filles au sein des enfants d'agriculteurs du collège général semble traduire un refus plus net de leur part.

Les explications données en dehors des réponses-types constituent en moyenne $20 \%$ de l'ensemble des réponses. Elles traduisent dlabordun sentiment d'incertitude en face de l'avenir de l'agriculture qui est partagé par des enfants d'agriculteurs appartenant aussi bien au collège général qulau C.E. A. "ce sera peut-être un métier qui disparaîtra dans 10 ou 20 ans, ou qui sera remplacé par les grandes exploitations". Pour cette raison, plusieurs enfants d'agriculteurs se voient déconseiller la profession agricole par leursparents; clest le cas dans le cycle long du C.E. A. et dans les sections "pratiques" du collège général. Ce trait oppose nettement les enfants d'agriculteurs du collège général qui sont entrés en 4 è ou 3è pratique et ceux qui ont rejoint le cycle court agricole après une classe de 5è. Selon les enseignants, le sentiment d'incertitude à l'égard de l'avenir se serait accru depuis quelques années, en particulier depuis la publication du Plan Mansholt et du Rapport Vedel.

D'autre part, cette perception del'avenir pousse certains élèves d'origine agricole à prendre le contre-pied de ceux de leurs camarades qui projettent d'être agricul teurs à cause de leur mauvaise réussite scolaire: "ll faudra à ceux-ci une formation élevée, car on ne connaît pas très exactement l'avenir de l'agriculture". II en est qui se découragent d'avance "parce quil y a trop de responsabilités", ou "parce qu'il faudra toujours faire des comptes". Les élèves d'origine non agricole du C.E. A. pensent également quili est "difficile de mener une exploitation".

De façon générale, les arguments de certains élèves qui n'envisagent pas d'être agriculteurs viennent contredireles raisons qui poussent d'autres élèves à vouloir entrer dans l'agriculture. Ceci est particulièrement net à l'égard de la liberté de l'agriculteur par exemple. Les enfants dont les parents ont de petites exploitations ne sont pas les seuls à faire des critiques, sur les servitudes de llélevage, la course aux investissements, le système des prix. Le recul dont témoigne ce jugement traduit en partiel'adoption d'un système de référence de type "urbain" vis à vis du choix de laprofession. Il exprime surtout une prise de conscience des conditions de vie diune fraction importante de la paysannerie. Les élèves d'origine non-agricole du C. E. A. accentuent cette 
analyse : "l'agriculture sera toujours parmi les classes défavorisées en France" déclare llun deux. Ce jugement montre comment les élèves d'origine non agricole contribuent à dévaluer limage que se font de l'agriculture les enfants d'agricul teurs eux-mêmes.

\section{Les interrogations de ceux qui hésitent}

L'ensemble de réponses que nous venons de présenter suffirait largement à définir le cadre de réflexion de ceux qui hésitent. Ceux-ci insistent plus particulièrement sur trois séries de problèmes : les diffi.cul tés d'installation et l'incertitude qui pèse sur l'avenir de l'agriculture, les chances de réussite dans les études, et la position sociale de l'agriculteur dans lasociété. Voici trois affirmations qui nous semblent significatives:

- "Aujourd'hui, il est très difficile de diresion va être agriculteur, car le monde agricole change rapidement (...). Il est difficile de s'installer car les fermes sont trop petites et donc peu rentables".

- "Si je n'ai pas la chance de réussir dans les examens futurs, peutêtre resterai-je à la ferme".

- "Etre agriculteur ne m'a jamais intéressé, mais je pense que ce qui m'a dérouté, clest la camaderie urbaine. Quand je suis avec quelqulun de la ville, je me sens un peu gêné de parler de la campagne".

En résumé, les élèves qui se détournent de l'agriculture le font parce qulil est difficile de s'installer sur de grandes exploitations, que les petites exploitations ne procurent qulun revenu bas et instable, que l'avenir de la profession est incertain, le travail pénible et astreignant, et que la condition paysanne est dévalorisée. Quant aux élèves qui envisagent d'entrer dans llagriculture, ils font rarement état des contraintes qui pèsent sur leur choix et se retranchent souvent derrière des réponses banales. Finalement, si les élèves ont donné dans leurs réponses un éventail à peu près complet de tous les avantages et inconvénients de la profession agricole, l'explication de beaucoup d'attitudes semble pouvoir être traduite en terme de comparaison de revenus entre llemploi agricole et llemploi non agricole. 


\section{CONCLUSION GENERALE}

L'étude monographique vient compléter dlun double point de vue l'enquête générale faite en Ille-et-Vilaine sur les relations entre éducation et mobilité en milieu agricole.

1) Elle fait apparaître que contrairement à l'enseignement agricole court qui fait le plus souvent entrer dans llagriculture, le cycle long en détourne d'autant plus que le niveau de formation atteint est plus élevé, pour orienter vers lesprofessions para-agricoles (1). Au niveau du baccalauréat $D^{\prime}$, on cherche même à rejoindre l'enseignement supérieur long. Quant àl'enseignement général secondaire, il oriente massivement non seulement hors de l'agricul ture mais hors dupara-agricole. Cesobservations sont conformes aux hypothèses émises et à certaines des constatations faites dans l'enquête générale d'llle-et-Vilaine; la portée des résultats de l'une et l'autre investigation s'en trouve accrue.

La monographie permet de connaître les raisons pour lesquelles les garçons d'origine agricole du cycle longagricole et du collège général se détournent du métier d'agriculteur : difficul tés d'installation, médiocrité et instabilité du revenu, caractères pénible et astreignant du travail, incertitude de l'avenir, sentiment d'une dévalorisation sociale de la profession agricole, ou parfois, complexité de la gestion diune exploitation agricole et poids des responsabilités exïgés.

2) Quant à l'étude comparée de l'orientation scolaire des enfants d'agriculteurs de l'enseignement agricole et de ceux de l'enseignement général, elle met en lumière les mécanismes dlentrée dans l'enseignement agricole. Cet enseignement ayant été conçu en vue de former les agriculteurs et les personnels des secteurs para-agricoles, on pourrait supposer que l lorientation scolaire est le résul tat des projets profes sionnels. Cette explication n'est qulen partie confirmée, car il semble qu'il y ait influence non seulement de perspectives diemploi mais aussi de déterminismes scolaires.

Ainsi, l'orientation vers le cycle court apparaît nettement commandée à la fois par l'échec scolaire dansl ienseignement général et par le projet dlexercer le métier agricole dans une exploitation familiale dont la dimension est élevée. Il est significatif que la taille de l'exploitation des parents soit très différente chez les enfants dlagriculteurs du cycle agricole court et chez ceux des classes pratiques de l'enseignement général.

(1)L'importance relative des taux d'entrée dans l'agriculture chez les élèves du cycle agricole court et chezles élèves du cycle long n'est pas conforme à ce que souhaite le groupe de travail professionnel qui, lors de la préparation du Vlème Plan pour la Bretagne, a étudié l'enseignement et la formation professionnelle en agricul ture. Ce groupe a fortement insisté sur le fait que le $B$. A. A. ne peut pas préparer à exercer la fonction de chef dientreprise agricole. 
46.

Les élèves d'origine agricole du cycle long, comme ceux du cycle court et à la différence de ceux du collège général, sont issus de grandes exploitations, circonstance favorable à la perspective de travailler dans l'agriculture elle-même ou un secteur proche. Un certain nombre d'entre eux aurait sans doutepu, continuer des études générales après le premier cycle secondaire. Mais ils ont l'espoir de trouver dans l'enseignement agricole une formation spécifique plus intéressante et comportant moins de risques d'échec. L'orientation repose ainsi en partie sur une auto-sélection fondée sur llappréciation objective, consciente ou non,des chances diaccès à tel ou tel type de formation et d'emploi.

Les comparaisons faites entre cycle agricole court et cycle agricole long, entre cycle agricole court et sections pratiques de l'enseignement général, entre cycle agricole long et second cycle de l'enseignement général ont permis de mettre en lumière les caractéristiques de recrutement et de débouchés des deux catégories d'enseignement agricole : le court et le long. Mais nos conclusions restent provisoires car elles sont seulement fondées sur une étude de cas. Certaines tendances peuvent être propres à linstitution étudiéequi est une institution privée et qui a la particularité de comporter un collège général et un collège agricole. En fait, compte tenu de premières informations sur divers établissements d'enseignement agricole, les mécanismes et tendances principales d'orientation décelés dans notre exemple semblent en partie général isables. Leur degré de validité sera tout au moins mis à l 'épreuve lors de nouvelles enquêtes qui porteront sur d'autres catégories d'établissements. 


\section{LISTE DES TABLEAUX}

pages

1 - Effectifs des élèves du collège agricole

2 - Effectifs des élèves du collège général

3 - Origine sociale des élèves selon la nature et le niveau de l'enseignement suivi (en \%)

4 - Age de sortie de l'école primaire selon l'orientation scolaire et l'origine sociale (en \%)

5 - Age de sortie de l'école primaire selon la nature et le niveau de l'enseignement suivi (en \%)

- Frères et soeurs des enfants d'agriculteurs du collège général et du collège agricole : type d'enseignement suivi au-delà du primaire par ceux qui sont en cours de scolarité

7 - Dimension de l'exploitation des parents selon la nature de

l'enseignement suivi par les enfants $(\%)$
- Bourses accordées aux enfants d'agriculteurs du collège agricole

9 - Bourses nationales accordées aux élèves des classes de 4è, 3è et 2 è du collège général

10 - Influences ayant pesé sur le choix de l'enseignement agricole selon llorigine scolaire des élèves (enfants dlagriculteurs uniquement) en \%

11 - Réponses à la question: "Si vos études étaient à recommencer souhaiteriez-vous faire la même chose ?" (en \%)

12 - L'enseignement agricole sous sa forme actuelle correspond-il
à ce qu'en attendent les élèves du collège agricole (en $\%$ )

12 - L'enseignement agricole sous sa forme actuelle correspon
à ce qu'en attendent les élèves du collège agricole (en $\%$ )

13 - Projets d'entrée dans l'agriculture selon la formation suivie - 36

14 - L'orientation des garçons vers les professions para-agricoles en fonction de la formation et de l'origine sociale

15 - Influence de la surface et des productions spécialisées sur l'entrée dans l'agricul ture au niveau du cycle long

16 - Raisons-types de la non-entrée dans l'agriculture déclarées par les élèves (en \%) 
INSTITUT NATIONAL DE LA RECHERCHE AGRONOMIQUE Station d'Economie Rurale de Rennes

FORMATION POST-SCOLAIRE ET EMPLOIS DES TRAVAILLEURS AGRICOLES DIILLE-ET-VILAINE QUI ONT DEMANDE OU OBTENU LES AIDES DU F.A.S.A.S.A. A LA CONVERSION

G. JEGOUZO avec la collaboration de B. ROZE 

Vue d'ensemble ___ 1

Introduction

I - L'entrée dans llagriculture suivie de sortie___ 9

- L'entrée dans l'agriculture __ 9

- Formation scolaire lors de la sortie _ 9

- Durée de présence dans llagriculture et âge de sortie 12

11 - La préformation et la formation de conversion___ 16

- Combien bénéficient d'une préformation ?-_ 16

- Nature et niveau de la formation de conversion_ 17

Il - Llaccès aux emplois non agricoles 20

- L'accès aux emplois para-agricoles _ 21

- Position dans la hiérarchie sociale_ 22. 


\section{VUE DIENSEMBLE}

Dans l'enquête par sondage faite en 1970 en Ille-et-Vilaine sur la formation et les emplois des enfants d'exploitants agricoles nés de 1945 à 1955, il est apparu queles jeunes qui sortent de llagriculture après y être entrés, n'ont qu'une formation scolaire de bas niveau (études primaires ou agricoles courtes). D ans quelle mesure reçoivent-ils une formation de conversion?

Depuis 1964, des aides financières particul ières sont attribuées, au titre du Fonds d'Action Sociale pour l'Aménagement des Structures Agricoles (F.A.S.A.S.A.), aux "mutants agricoles" qui apprennent un nouveau métier, ou se qual ifient, lorsqulils quittent llagriculture. Aussi, avons-nous complété notre enquête par sondage en exploitant, de façon exhaustive, les dossiers administratifs établis par les organismes chargés de gérer les actions du F. A.S. A.S. A. - il slagit, depuis janvier 1968, du Centre National pour I'Aménagement des Structures des Exploitations Agricoles (C. N. A.S.E.A.). Dans les générations retenues, qui sont celles nées de 1945 et après, 1304 candidatures se sont manifestées au 31 décembre 1969.

Les données recueillies sont auplus descriptives, et ne sont pas toujours satisfaisantes. Mais comparées aux informations de l'enquête par sondage précitée, elles permettent non seulement d'apporter un supplément de connaissance sur la formation de conversion des travailleurs qui sortent de l'agriculture après y être entrés, mais de quantifier, en partie, les résultats obtenus, en Ille-et-Vilaine, danslapolitique de réemploi entreprise au titre du F.A.S. A.S. A. . Comme ce département a des caractéristiques socio-économiques particulières, les tendances qui $y$ ont été mises en lumière ne sont pas toujours extrapolables.

Les principales observations faites sur la base des relevés sont les suivantes:

1 - Parmi les actifs agricoles des générations 1945 à 1951 qui, début 1970 , sont sortis de l'agriculture après y être entrés, la proportion de ceux qui ont sollicité les aides du F.A.S.A.S. A. s'établit à environ $24 \%$ pour les garçons et $8 \%$ pour les filles. Malgréla politique d'aide au réemploi la majorité des mutants agricoles des générations considérées, quitte l'agriculture sans qualification. Ce sont le plus souvent les filles qui se présentent sur le marché du travail dans les plus mauvaises conditions de formation.

2 - Les mutants candidats auxaides à la conversion possèdent plus fréquemment que les autres sortants, une formation agricole ou générale secondaire, surtout chez lesfilles. Les chances dlaccès à la, promotion sociale ne sont pas égales pour tous et.toutes, cantrairement à ce quion pourrait penser.

3 - Les aides du F.A.S.A.S. A. sont souvent demandées dès que l'âge minimum requis est atteint (17 et 18 ans). L'entrée dans llagriculture a donc été de courte durée. Fréquemment, les mutants viennent à peine de 
terminer leur scolarité - et en particulier, leur formation agricole lorsquils s'engagent dans llapprentissage d'un métier non agricole par la voie de la promotion sociale. Il apparaît bienquel'origine du processus qui alimente l'entrée dansllagriculture, puis l'entrée dans les centres de promotion sociale, est à rechercher dans les mauvais résultats scolaires ou les erreurs d'orientation scolaire. L'intervention du F. A.S. A. S. A. sleffectue de manière telle qu'elle témoigne des échecs dlune partie du système scolaire agricole et non agricole, du sur-développement de l'enseignement agricole court, du sous-développement de l'enseignement technique. Dans le même temps qu'on prépare plusieurs milliers de garçons et de filles au Brevet d'Apprentissage Agricole (B. A. A.) on finance les études post-scolaires d'une partie de ceux qui viennent d'obtenir ce diplôme. Parfois même tout se passe comme sill'existence des aides du F. A. S. A.S.A. à la conversion était une incitation à entrer dans l'agriculture et dans l'enseignement agricole à temps partiel. Il y a plusieurs raisons pour qu'un tel système de formationscolaire et postscolaire tende à se maintenir.

4 - La formation de promotion sociale a permis au groupe de jeunes que nous avons étudié, d'atteindre le plus souvent $(88,5 \%$ des garçons et $52,8 \%$ des filles) un niveau $V$ (qualification équivalente à un $C_{0} . A_{0} . P_{0}$ ) moins souvent $(11,5 \%$ des garçons mais $47,2 \%$ des filles) un niveau IV (qualification équivalente à un Brevet de technicien). Les centres de pro-motion sociale, en sladressant à de tout jeunes adultes, ont ainsi surtout office

a) d'enseignement technique court pour ceux qui ont une formation scolaire primaire (filles et garçons) ou de niveau B. A. A. (garçons)

b) d'enseignement long, agricole ou technique, d'une partpour un certain nombre de filles de niveau $B$. A. A。, d'autrepartpour les garçons et filles de niveau Brevet Professionnel Agricole ou du 1er cycle de llenseignement général.

Ces fonctionspourront être assurées au mieuxsi le stage de promotion est précédé d'une préformation. La fréquence de la préformation apparaît faible dans le groupe des mutants ici étudiés ( 1 garçon sur 5, 1 filles sur 4), et n'est quinfirme si on considère le total des enfants sortis de liagriculture après y être entrés.

5 - Lors de lacréation du F.A.S.A.S.A., il avait été souhaité que les mutants agricoles, bénéficiaires des aides publiques à la conversion, s'orientent vers les secteurs para-agricoles, ceux-ci contribuant directement au développement du secteur proprement agricole. Pour 29, 1 \% des filles et $14,4 \%$ des garçons, la première profession après la for-mation est exercée dans ces secteurs.

Chez les garçons, les crédits du F. A. S. A. S. A. contribuent surtout à satisfaire l'offre d'emploi du bâtiment.

6 - Alors que la majorité des mutantes observées dans llenquête par sondage étaient ouvrières ou employées de maison, la majorité de celles qui ont bénéficié des aides à la formation $(77,7 \%)$ sont employées de bureau et cadres moyens.

Chez les garçons, les cadres moyens sont un peu moins rares parmi les titulaires dela promotion sociale $(7,6 \%)$ que dans l'ensemble des mutants $(2,9 \%)$. Mais parmi les uns et les autres, la catégorie des 
ouvriers prédomine. Les informations utilisées ne permettent pas de déterminer à quel niveau de la hiérarchie ouvrière les bénéfiaires des aides du F. A. S. A.S.A. se trouvent classés lors de leur premier em. ploi. 


\section{INTRODUCTION}

Une information supplémentaire sur la formation post-scolaire et sur les emplois des enfants d'agriculteurs qui sortent de llagricul_ ture après y être entrés.

Dans l'enquête par sondage faite en Ille-et-Vilaine sur la formation (scolaire et post-scolaire) et les emplois (ágricoles et non agricoles) des enfants d'exploitants agricoles nés de 1945 à 1955, llorientation d'emploi a été analysée en distinguant :

- les enfants qui n'entrent pas dans l'agriculture lors de leur premier emploi,

- ceux qui entrent dans llagriculture puis en sortent après un temps plus ou moins long d'activité agricole (au moins 3 mois); notons que ces sortants sont souvent appelés "mutants";

- ceux qui entrent dans l'agriculture et s'y trouvent encore à la date de l'enquête.

Il est apparu que les garçons et filles qui, au moment où ils commencent à travailler, ont comme catégorie dléducation la plus élevée la formation primaire ou la formation agricole courte, entrent le plus souvent dans l'agriculture. Quandl'orientation vers l'agriculture se fait après l'école primaire, elle coincide avec l'entrée dans l'enseignement agricole à temps partiel. Ensuite, se produisent des sorties importantes après une durée souvent courte d'activité agricole. A 20-24 ans, seulement un peuplus du 1/4 des garçons et filles étudiés sont actifs agricoles.

Quand ces jeunes de formation primaire ou agricole courte quittent llactivité agricole, le risque est grand qulils se présentent sans qualification sur le marché du travail non agricole. Dans quelle mesure bénéficient-ils, à ce stade, des actions de préformationprofessionnelle et de promotion sociale (1) qui sont organisées pour faciliter les conversions?

L'échantillon étudié était trop faible pour effectuer une bonne analyse de la formation post-scolaire des enfants nés en IIle-et-Vilaine en 1945 et après. Parmi les jeunes qui sont sortis de l'agriculture après y être entrés, le nombre de cas de formation de conversion,

(1) Rappelons que la préformation professionnelle est une action d'orientation d'une part, d'élévation duniveau des connaissances de base dlautre part. Quant à la promotion sociale, elle correspond à "toute action de formation ou de perfectionnement, de quelque nature qu'elle soit,quelque niveau qu'elle se situe, dès lors qu'elle s'adresse à une personne déjà engagée dans la vie professionnelle". Ajoutons que l'enseignement post-scolaire se définit comme "celui qui est reçu après une interruption des études qui n'est pas motivée par la maladie ou le service militaire". 
obt enue ou en cours d'obtention à la date de l'enquête, était seulement le suivant :

- sur 98 garçons : 26 dont 13 de niveauprimaire et 13 de niveau brevet d'apprentissage agricole (B. A. A.)

- sur 85 filles : 8 dont 2 de niveau primaire et 5 de niveau B. A. A.

Comme depuis 1964, des aides financières particulières sont attribuées, au titre du F.A.S.A.S.A., aux "mutants agricoles" pour quils apprennent un nouveau métier, nous avons recherché dans la documentation administrative un complément d'information sur la promotion sociale et le réemploi des jeunes qui sortent de llagriculture. Nous avons ainsi exploité les dossiers détenus par le C.N.A.S.E. A. pour les actifs agricoles d'llle-et-Vilaine qui se sont portés candidats aux aides à llapprentissage d'un nouveau métier.

Importance relative et caractèresde la population étudiée

L'observation porte sur 968 garçons et 336 filles, soit 1304 cas. Il s'agit de relevés exhaustifs pour les jeunes qui se caractérisent comme suit :

- lls sont nés en 1945 et après, comme les enfants étudiés dans l'enquête statistique. Pusprécisément la quasi-totalité appartient aux générations 1945 à 1951 ( 1270 cas).

- Lors de leur demande d'aide au F.A.S.A.S.A. ; ils étaient domiciliés en Ille-et-Vilaine et travaillaient dans llagriculture comme aides familiaux ( $82 \%$ des garçons et $99 \%$ des filles) ou salariés des exploitations agricoles. Un certain nombre de ces salariés sont eux-mêmes enfants d'exploitants agricoles.

- Ils se sont portés candidats aux aides à la conversion entre le début d'attribution des prestations (1964) et le 31 décembre 1969. Ils remplissaient donc, le plus souvent, les conditions prévues pour obtenir les aides sollicitées. On ne saisit de ce fait qu'une partie des mutants qui suivent une formation de conversion; aucun organisme administratif ne regroupe les données relatives à tous les mutants agricoles qui apprennent un métier non agricole lors de leur: conversion. $91 \%$ des garçons et $97 \%$ des filles ont eu leur demande dlaide acceptée. Ceux qui sont revenus dans l'agriculture après avoir commencé à exercer un emploi non agricole, ont été exclus des relevés.

Les dossiers du C.N.A.S.E. A. permettent dlatteindre uncertain flux de sorties hors de l'agriculture. Quelle est l limportance relative de ce flux dans l'ensemble des sorties qui, fin 1969 ou début 1970 , se sont produites dans les générations considérées ? On ne peut en donner qulune estimation approximative, ne serait-ce que parce que les relevés au C.N.A.S.E.A. portent sur quelques enfants de salariés agricoles à la différence de l'enquête statistique.

Début 1970 , les enfants d'exploitants agricoles nés de 1945 à 1951 avaient atteint l'âge minimum requis ( 17 et 18 ans)pour bénéficier des aides àla mutation. $38 \%$ des garçonset $37 \%$ des filles de ces générations sont entrés dans l'agriculture puis en sont sortis lors de 
l'enquête statistique, ces pourcentages étant calculés sur l'ensemble des actifs et inactifs. En appliquant ces proportions au nombre estimé d'enfants nés de 1945 à 1951, qui survivent début 1970, on obtient un flux total de sorties dienviron 4000 garçons et 4000 filles. Une fraction seulement de ces sortants a pusolliciterllaide du F. A。 S. A。S.A. puisque certains ont quitté l'agriculture avant l'entrée en application de la législation, et que dlautres ne remplissaient pas les conditions requises pour en bénéficier. Le pourcentage des sortants qui se sont portés candidats s'établ it pour les garçons à 968 sur 4000 soit $24 \%$, pour les filles à 336 sur 4000 soit $8 \%$ 。

Ces ordres de grandeur ne sont qulapproximatifs mais sont peu différents des résultats de lienquête statistique. En effet, 26,5\% des garçons sortants et $9 \%$ des sortantes (inactives exclues) avaient obtenu une formation de conversion ou étaient en cours de stage, lors des interviews.

Ainsi, les mesuresprises au titre du F.A.S.A.S.A. n'ont bénéficié jusquià présent qulà une fraction limitée des sortants, surtout chez les filles. Nous n'avonspas les données nécessaires pour mettre en lumière les multiples raisons de ce phénomène. Ces raisons sont à rechercher à la fois du côté de lloffre et de la demande de promotion sociale. Notons seulement que les candidatures aux aides à la sortie ont augmenté d'année en année entre 1964 et 1969 ; pour notre population la série est la suivante : 150 en 1964, 150 en 1965, 170 en 1966, 228 en 1967,272 en 1968 et 334 en 1969.

Sil faut savoir que le flux de sorties saisi dans nos relevés est très restreint, il faut aussi ne pas perdre de vide que la population considérée se trouve dans des situations très diverses au moment où nous avons dépouillé les dossiers du C.N.A.S.E. A. En effet, que la demande d'aide ait été acceptée ou refusée, les candidats occupent l'une des huit positions suivantes:

- ont commencé à exẹcer un emploi après avoir reçu une formation, - ont commencé à exercer un emploi sans avoir reçu de formation ou après avoir interrompu leur stage de formation ou de préformation, - ont terminé leur formation mais n'ont pas débuté dans leur nouvel emploi,

- sont en cours de formation,

- ont terminé leur préformation mais $n^{1}$ ont pas commencé leur formation,

- sont en cours de préformation,

- ne sont pas encore entrés en stage de préformation ou de formation ; certains de ceux-ci se trouvent au service militaire, - n'ont pas donné suite à leur demande.

Nature et qualité des informations analysées

Les informations disponibles dans les dossiers consultés se rapportent d'une part à l'entrée dansl'agriculture et à la situation de formation et d'emploi lors de la candidature au C. N. A. S. E. A., d'autre part aux stages de préformation et de formation, enfin au 1 er emploi non agricole exercé après la formation ainsi qu'à l'emploi occupé 6 mois plus tard. On dispose ainsi de plusieurs renseignements identiques à ceux collectés dans l'enquête par interviews. 
8.

Slagissant de la qualité des données recueillies, il faut faire les réserves d'usage relatives aux statistiques dlorigine administrative (1). La formation scolaire est loin d'être bien connue. Tantôt elle n!a pas été déclarée et tantôt la déclaration est imprécise. On ne peut pas retracer le cursus scolaire et on ne dispose que de quelques éléments du cursus professionnel. Le dépouillement effectué semble cependant utile puisqu'il permet de mieuxconnaître un phénomène social majeur : le réemploi des jeunes qui sortent de llagriculture.

\section{Présentation des résultats}

On slattachera à reconstituer une partie de l'histoire professionnelle des jeunes qui ont un dossier au C. N. A. S.E. A. en présen:tant successivement :

- l'entrée provisoire dans l'agriculture,

- l'étape de la préformation et de la formation de conversion,

- la phase diinsertion dans les activités non agricoles.

La préformation et la formation n'ont été analysées que pour ceux qui ont à la fois obtenullaide du F.A.S.A.S. A. et terminé leurs stages. Quant aux nouveaux emplois, ils ne sont décrits que pour ceux qui ont commencé à exercer une profession non agricole après avoir reçu une formation. Précisons qu'un certain nombre de candidats aux aides à la conversion ne suivent pas de stage de formation mais réalisent un placement direct.

La population des sortants observée au C.N.A.S.E.A. sera comparée au groupe des sortants étudiés dans l'enquête par interviews (2). Ceci permettra d'apprécier, en partie, les résultats obtenus en IIle-et-Vilaine dans la politique de sortie conduite au titre du F. A. S. A. S. A. .

(1) Se reporter sur ce point à une note du Service Central des Enquêtes et Etudes Statistiques au Ministère de l'Agriculture : "Note sur les conditions diutilisation statistique des sous-produits administratifs dans le domaine agricole", ronéo, 16 octobre 1970.

(2) Ce qui constituelloriginalité de cette analyse par rapport à diverses études traitant des seuls mutants passés par le C.N.A.S. E. A. . 


\section{1 - L'ENTREE DANS L'AGRICULTURE SUIVIE DE SORTIE}

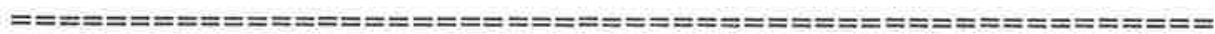

\section{L'entrée dans l'agricul ture}

Selon l'enquête par sondage, le mode le plus courant d'entrée dans llagriculture est le suivant pour les générations 1945-1955. A la fin de la scolarité obligatoire, il y a arrêt des études à temps complet et début de l'activité agricole. Pour que les parents puissent continuer à percevoir les allocations familiales jusqu'à ce que l'enfant ait atteint l'âge de 18 ans, celui-ci se trouve inscrit à des cours postscolaires agricoles ou à un enseignement agricole à temps partiel.

Ce schéma se retrouve chez les mutants passés par le C. N. A. S.E.A. . En effet, ils ont; le plus souvent, commencé à exercer llactivité agricole à la fin de la scolarité obligatoire; $97 \%$ des garçons et $92 \%$ des filles sont entrés dans llagriculture à 13-14-15 ans (âge en années révolues). Rares sont ceux qui ont poursuivi des études secondaires générales ou agricoles à temps plein, et sont devenus actifs agricoles à 16 ans et plus. Notons, que du fait de leur année de naissance, à peu près tousles jeunes étudiés au C.N.A.S.E. A. n'ont été soumis à l'obligation scolaire que jusqu'à 14 ans.

Age dientrée dans llagriculture

\begin{tabular}{|c|c|c|c|c|c|c|c|c|c|c|}
\cline { 2 - 9 } \multicolumn{1}{c|}{} & $\begin{array}{c}13 \text { ans } \\
\text { ou } \\
\text { moins }\end{array}$ & 14 & 15 & 16 & 17 & 18 & 19 & 20 & $\begin{array}{c}\text { Total } \\
\text { des cas } \\
\text { précisés }\end{array}$ & $\begin{array}{c}\text { Cas } \\
\text { non } \\
\text { précisés }\end{array}$ \\
\hline \begin{tabular}{c} 
Garcons \\
\hline $\begin{array}{c}\text { nombre } \\
\%\end{array}$
\end{tabular} & $\begin{array}{c}70 \\
7,3\end{array}$ & $\begin{array}{c}795 \\
82,6\end{array}$ & $\begin{array}{c}71 \\
7,4\end{array}$ & $\begin{array}{c}13 \\
1,3\end{array}$ & $\begin{array}{c}6 \\
0,6\end{array}$ & $\begin{array}{c}6 \\
0,6\end{array}$ & $\begin{array}{c}1 \\
0,1\end{array}$ & $\begin{array}{c}1 \\
0,1\end{array}$ & $\begin{array}{c}963 \\
100\end{array}$ & 5 \\
\hline $\begin{array}{c}\text { Filles } \\
\begin{array}{c}\text { nombre } \\
\%\end{array}\end{array}$ & 15 & 259 & 34 & 17 & 6 & 4 & - & 1 & 336 & - \\
\hline
\end{tabular}

Ĺes diplômes scolaires possédés lors du dépôt de candidature reflètent l'entrée précoce dans llagriculture.

\section{Formation scolaire lors de la sortie}

La grande distinction se fait entre ceux qui ont acquis les diplômes de l'enseignement agricole court (brevet d'apprentissage agricole 
10.

ou ménageragricole-B. A. A. ou B. A. M. A. - et brevet professionnel agricole ou ménager agricole-B.P. A. ou B.P.M. A.) et ceux qui ne les ayant pas obtenu, n'ont comme niveau le plus élevé que la formation primaire (1), étant entendu qu'à celle-ci se sont toujours ajoutés au moins quelques "cours post-scolaires agricoles". Les autres, une petite minorité, ont un diplôme agricoleplus élevé (brevet d'enseignement agricole, B.E. A. , brevet d'agent technique agricole, B. A. T. A. , brevet de technicien agricole, B. T. A.) ou un diplôme de l'enseignement général secondaire (B.E.P.C. et très exceptionnellement le baccalauréat).

Le niveau de formation apparaît nettement plus faible chez les garçons que chez les filles. $53 \%$ des premiers ont au plus un niveau primaire contre $15 \%$ des secondes. Les filles ont proportionnellement plus souvent le B.A.A. ou B. A. M. A. $(49 \%$ contre $33 \%)$, le B.P.A. $(19 \%$ contre $8 \%)$, un autre diplôme agricole $(6,5 \%$ contre $3 \%)$ ou le B.E.P.C. $(10 \%$ contre $2 \%)$. Le flux de sortie quipasse parleC.N.A. S.E. A. n'est donc pas complètement le même, de ce point de vue, pour les filles et les garçons.

La comparaison des formations scolaires des candidats aux aides à la mutation et des mutants saisis dans l'enquête statistique révèle que l'action du F. A.S. A.S. A. bénéficie proportionnellement plus souvent aux mutants diplômés de l'enseignement agricole ou de l'enseignement général secondaire qulà ceuxde niveau primaire. Les chances d'accès à la promotion sociale sont inégales selon les niveaux de formation scolaire (2), si tout au moins on fait l'hypothèse que les conditions d'accès aux aides à la conversion sont aussi fréquemment remplies quel que soit le niveau de formation.

(1) Il n'a pas étépossible de les répartir de façon sûre entre ceux qui ont le C.E.P. et ceux qui ne l'ont pas.

(2) Ceci avait déjà été observé dans l'enquête statistique;op. cit.p. 64. 
Formation scolaire la plus élevée des candidats aux aides du F, A。 S. A。 S. A. et de

l'ensemble des mutants

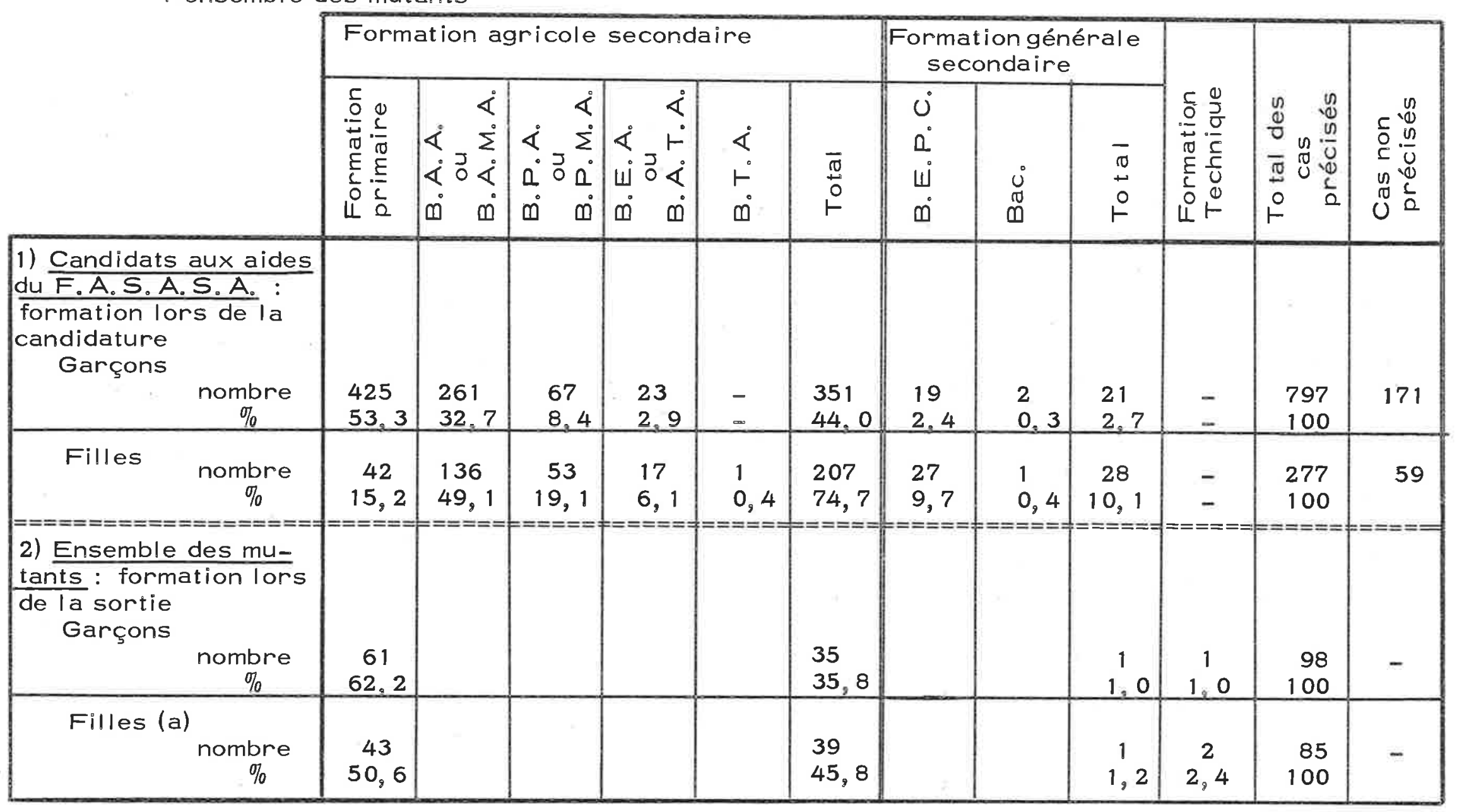

(a) les inactives lors de l'enquête étant exclues. 
12.

Durée de présence dans llagriculture et âge de sortie

Qu'il s'agisse des garçons ou des filles, llactivité agricole a été de courte durée puisque dans environ 2 cas sur 3 , elle a été exercée pendant seulement 3 et 4 ans (en années révolues). Un peu plus de la moitié des garçons et filles ont été actifs agricoles pendant moins de 4 ans, ce qui est une proportion équival ente à celle observée dans l'enquête par sondage. Mais dans cette enquềte, le tiers des jeunes sortis de l'agriculture y avaient travaillépendant moins de 3 ans, et nlavaient donc pas atteint la durée minimale requise pour avoir droit aux prestations du F.A.S. A. S. A. . En effet, jusqulà un décret de février 1969, il fallait être âgé d'au moins 17 ans et avoir été actif agricole à titre principal pendant au moins 3 ans (1) pour avoir droit aux avantages accordés au titre du F.A.S.A.S.A., les années de formation agricole par alternance étant considérées comme années dlactivité agricole. Selon la nouvelle règlementation, llâge minimum est de 18 ans et l'ancienneté d'emploi agricole de 1 an, le temps de scolarité agricole à temps partiel étant cette fois exclu.

Durée de llactivité agricole lors de la demande d'aide du F.A.S. A.S.A.

\begin{tabular}{|c|c|c|c|c|c|c|c|c|c|c|}
\hline & $\begin{array}{l}1 \text { an } \\
\text { ou } \\
\text { moins }\end{array}$ & 2 ans & 3 & 4 & 5 & 6 & 7 & $\begin{array}{l}8 \text { ans } \\
\text { et } \\
\text { plus }\end{array}$ & \begin{tabular}{|l|} 
Total \\
des cas \\
précisés
\end{tabular} & $\begin{array}{c}\text { Cas } \\
\text { non } \\
\text { précisés }\end{array}$ \\
\hline$\frac{\text { Garcons }}{\substack{\text { nombre } \\
\%}}$ & $\begin{array}{l}15 \\
1,6\end{array}$ & $\begin{array}{l}65 \\
6,8\end{array}$ & $\begin{array}{l}452 \\
47,0\end{array}$ & $\begin{array}{l}176 \\
18,3\end{array}$ & $\begin{array}{l}172 \\
17,9\end{array}$ & $\begin{array}{l}46 \\
4,8\end{array}$ & $\begin{array}{l}23 \\
2,4\end{array}$ & $\begin{array}{l}12 \\
1,2\end{array}$ & $\begin{array}{l}961 \\
100\end{array}$ & ris o \\
\hline \multicolumn{11}{|l|}{ Filles } \\
\hline$\underset{\%}{\text { nombre }_{\%}}$ & $\begin{array}{l}10 \\
3,0\end{array}$ & $\begin{array}{l}21 \\
6,3\end{array}$ & $\begin{array}{l}152 \\
45,2\end{array}$ & $\begin{array}{c}66 \\
19,6\end{array}$ & $\begin{array}{c}34 \\
10,1\end{array}$ & $\begin{array}{l}23 \\
6,8\end{array}$ & $\begin{array}{l}15 \\
4,5\end{array}$ & $\begin{array}{l}15 \\
4,5 \\
\end{array}$ & $\begin{array}{l}336 \\
100 \\
\end{array}$ & - \\
\hline
\end{tabular}

On avait observé dans l'enquête par sondage qulau moins chez les garçons, la formation agricole courte retient davantage dans llagriculture que la formation primaire. On constate ici que les titulaires de diplômes agricoles sortent moins rapidement de l'agriculture que ceux qui ont seulement un niveau primaire, alors qu'ils appartiennent aux mêmes générations. $35 \%$ des garçons titulaires du B. A. A. et $38 \%$ de ceux qui ont le B.P.A. sont restés 5 ans et plus dans liagriculture; ces proportions sont bienplus élevées que pour l'ensemble des garçons considérés.

(1) A l'origine de llapplication dela législation, les salariés agricoles devaient être restés dans l'agriculture pendant 5 ans. 
Comme l'entrée dans l'agriculture a été souvent provisoire, nombreuses sont les candidatures qui ont été faites dès liâge de 17 ans et 18 ans ( $63 \%$ des garçons et $61,5 \%$ des filles). Un quart seulement des garçons ont été candidats à 20-21 ans, c'est-à-dire aussitôt, ou presque aussitôt, après le service militaire.

Slil apparaît qulune majorité de sortants, candidats à l'aide du F.A.S.A.S.A., sont très jeunes et ne sont restés dans l'agriculture qulun court laps de temps, clest en partie parce que, fin 1969, les générations observées n'ont pas encore atteint 20 ans; au 1.1.1970, la génération 1950 atteint 19 ans et celle de 1951,:18 ans. II n'en reste pas moins que, fréquemment, les enfants diagriculteurs viennent à peine de terminer leur scolarité quilil leut faut déjà envisager d'apprendre un métier non agricole par la voie de la promotion sociale. Cette voie représente sans doute pour les parents, le mode le moins coûteux d'acquisition, par les enfants, dlune formation professionnelle non agricole, ainsi que nous l'avons déjà relevé (1). L'entrée dans l'agriculture ne s'est-elle pas produite, dans un certain nombre de cas, seulement dans l'attente de percevoir les aides financières à la conversion? Tout se passe comme si un tel calcul était fait parfois, ce qui impliquerait que lintervention du F.A.S.A.S.A. encouragel'entrée dans l'agriculture et dans l'enseignement agricole à temps partiel. Mais il n'en est généralement pas ainsi, les parents étant trop ignorants des diverses formes de préparation aux emplois non agricoles. Le principal résultat de la politique d'aide à la conversion n'est pas de faire entrer des jeunes dans l'agriculture, mais de faire sortir des jeunes qui s'y trouvent à la suite diune mauvaise orientation scolaire et professionnelle (2).

Age lors de la demande diaide du F.A.S:A.S.A.

\begin{tabular}{|c|c|c|c|c|c|c|c|c|c|c|}
\hline & 16 ans & 17 & 18 & 19 & 20 & 21 & 22 & 23 & 24 & Total \\
\hline $\begin{array}{c}\text { Garçons } \\
\text { nombre } \\
\%\end{array}$ & 11 & 397 & 214 & 68 & 158 & 79 & 29 & 10 & 2 & 968 \\
\hline Filles & 1,1 & 41,0 & 22,1 & 7,0 & 16,3 & 8,2 & 3,0 & 1,1 & 0,2 & 100 \\
\hline $\begin{array}{c}\text { nombre } \\
\%\end{array}$ & 2 & 101 & 106 & 47 & 34 & 26 & 12 & 6 & 2 & 336 \\
\hline
\end{tabular}

Selon les résultats de l'enquête par sondage, les taux de sortie hors de l'agriculture diminuent lorsque la superficie de l'exploitation des parents augmente, une surface plus grande impliquant, toutes choses égales par ailleurs, davantage de possibil ités de placement dans llagriculture et des perspectives de revenus plus élevés. Comme le bénéfice des aides à la conversion était réservé, jusque fin 1969 , aux travailleurs agricoles considérés comme en surnombre, il est normal que les garçons et filles étudiés soient issus d'exploitations à forte

(1) Compte-rendu de l'enquête statistique, p. 21.

(2) Le rapport d'activité du C.N.A.S.E.A. pour llannée 1969 signale que la proportion de candidats moins jeunes s'accroît dans le temps. 
14.

densité de main-d'oeuvre (explaitationsde moins de 5 ha à 2 ou 3 travailleurs à temps plein, exploitations de 5 à 25 hà̀ 3 ou 4 travailleurs, exploitations de 25 ha et plus à 4 et 5 travailleurs).

Ajoutons que le nombre de candidats varie beaucoup selon les cantons. Ils sont les moins nombreux au nord du département et dans le bassin de Rennes, lesplus nombreux dans les deux zones suivantes: au sud-est du département dans la région de Vitré-La Guerche, au sudouest dans quelques cantons du pays de Rennes. Les facteurs qui peuvent expliquer de telles variations sont multiples. Notons seulement que le sud-est et le sud-ouest font partie des zones dudépartement où l'enseignement secondaire général et l'enseignement technique sont le moins développés. 
Répartition par canton des candidats et candidates à l'aide à la conversion

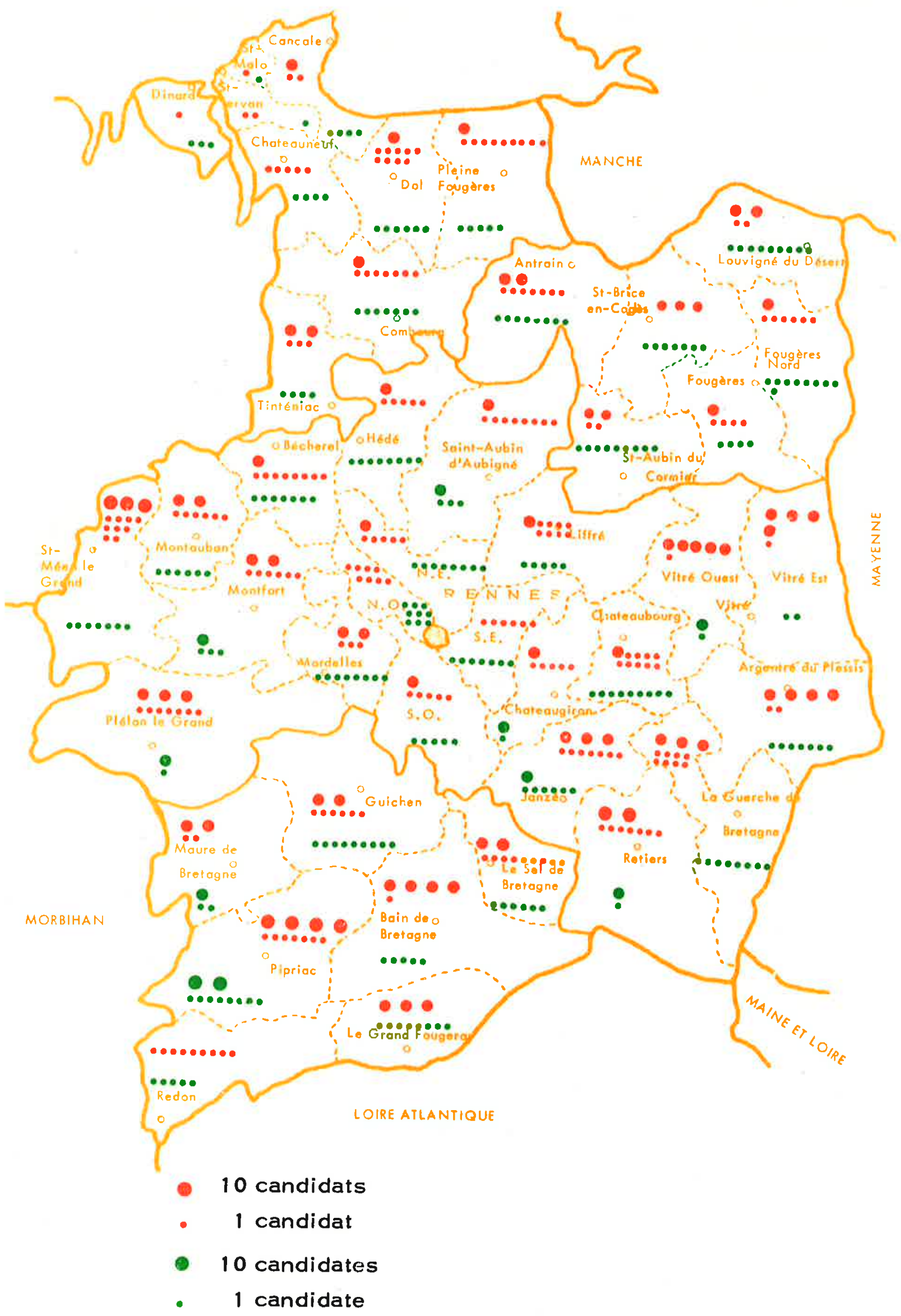


16.

II - LA PREFORMATION ET LA FORMATION DE CONVERSION

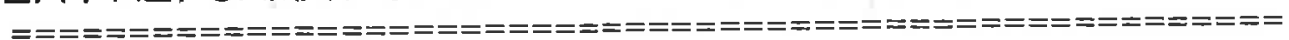

\section{Combien bénéficient. dlune préformation ?}

La préformation étant une action peu connue en dehors des milieux spécialisés, rappelons quels sont ses objectifs et son organisation. Nous avons vu que la formation de base des actifs agricoles qui sortent de llagriculture est généralement faible. Ceci a pour conséquence de restreindre le choix entre formation de conversion de niveau $\checkmark$ (qualification équivalente à un C. A.P.) et formation de niveau IV (qualification équivalente à un brevet de technicien), sinon, parfois, d'interdire l'entrée dans les centres de niveau $V$. D'autre part, les mutants agricoles ignorent, le plus souvent, les diverses possibilités de formation et d'emploi qui leur sont offertes. Clest essentiellement pour remédier à cette double lacune qulont été créés des centres de préformation. Les uns l'ont été à l'initiative d'organismesprivés (centres de llunion Nationale des Maisons Familiales), d'autres, depuis 1966 , par plusieurs Ministères ("Centres de promotion et diorientation des agriculteurs", C.E.P.R.O.D. A. ). Enfin, depuis 1968, I'Association Nationale pour la Formation des Adultes a ouvert plusieurs Centres destinés à tous les jeunes, qu'ils soient ou non d'origine agricole.

L'organisation de la préformation est hétérogène, les durées de stages et les formations dispensées sont variables. II faut relever que les C.E.P.R.O.D.A. et les centres de l'A.F.P.A. permettent essentiellement d'effectuer de courts stages diorientation, alors que dans les autres centres il y a à la fois orientation et formation.

Vilaine :

Trois centres de préformation se trouvent implantés en llle-et- Un Centre de Préformation Féminine ouvert en octobre 1965, qui permet, à la sortie, d'accéder à une formation de niveau Vou, moins fréquemment, de niveau IV.

- Un C.E.P.R. O.D.A. créé en janvier 1966 ; des stages de 3 mois permettent à des garçons d'entrer ensuite dans des centres de formation de niveau $V$.

- Un Centre de Préformation et de Promotion Sociale de Montfort, en activité depuis 1966, qui oriente vers des études post-scolaires de Brevet de Technicien Agricole (niveau IV) et de Brevet de Technicien Supérieur Agricole (niveau 1II) ou vers des centres de F.P. A. - 2è degré (niveau IV). Les jeunes considérés dans cette étude ont pu évidemment accomplir un stage de préformation soit dans/lun de ces centres, soit en dehors du département.

Malgré llampleur des besoins, l'offre de préformation est restée très limitée jusqulà présent comme liindique le nombre de bénéficiaires. Dans llexemple étudié, on a examiné combien parmi les jeunes qui, lors de nos relevés, avaient terminé leur formation de conver- 
sion, avaient, au préalable, reçu une préformation (1). On a recensé seulement 140 cas pour les garçons et 44 pour les filles parmi les 649 garçons et 173 filles qui ont terminé llapprentissage proprement dit de leur nouveau métier. Si la fréquence, en valeurs absolue et relative, de la préformation apparaît faible dans le groupe de mutants ici étudiés (22 \% pour les garçons et $25 \%$ pour les filles), elle est infime quand on considère le total des mutants des générations concernées. Ces évaluations ne sauraient être extrapolés à d'autres départements car l'offre de préformation est plus importante en Ille-et-Vilaine que dans la plupart des autres départements.

Les garçons ont effectué leur stage en C.E.P.R.O.D. A. (95 cas), en centres gérés par llUnion des Maisons Familiales (34 cas), et en centres F.P.A. (11 cas). Les filles ont fréquenté le centre de préformation féminine dillle-et-Vilaine (29) et des centres de Maisons Familiales (15).

Alors que chez les filles, le taux depréformation est plus élevé parmi celles qui ont un niveau primaire $(48 \%)$ que parmi celles qui ont le B.A.A. $(22 \%)$ ou le B.P.A. (22 \%), une tendance inverse se manifeste pour les garçons. Chez ceux-ci, le taux de préformation augmente quand la formation scolaire augmente (respectivement $17 \%$ au niveau primaire contre $22 \%$ et $47,5 \%$ chez les titulaires de B. A. A. d'une part, de B.P.A. et de B.E.A. d'autrepart). Ceci est en partie en relation avec le nombre de places offertes dans les deux types de centres de préformation, centres d'orientation d'une part, centres d'orientation et de formation dlautre part.

\section{Nature et niveau de la formation de conversion}

Les deux principaux cadres de formation de conversion sont : - pour les garçons : la F.P.A. (528 cas; $81 \%)$ et la Promotion Sociale dite Agricole (91 cas; $14 \%)(2)$.

- pour les filles : la Promotion Sociale Agricole (85 cas; $49 \%$ ) et la F.P. A. ( 37 cas).

Il y a à peu près égalité entre le nombre de garçons et le nombre de filles formés en promotion agricole alors qü'én F.'P. A. , le rapport de l'effectif féminin à lleffectif mascul in n'est que de $7 \%$. La rareté des centres féminins de F."P. A. est bien la cause principale du moindre développement de la formation de conversion chez les filles. II faut ajouter que certaines sections techniques seraient ouvertes aux filles si les employeurs manifestaient moins de réticence à les embaucher à la sortie.

(1) Notons que les stagiaires des centres de préformation ne font pas nécessairement ensuite un stage de formation.

(2) La "Promotion sociale agricole "est assurée par des centres agréés par le Ministère de l'Agriculture. Comme une partie de l'enseignement agricole, elle prépare à des métiers annexes dellagriculture, aux métiers de l'industrie laitière ou de la viande, à des carrières de techniciens, de vulgarisateurs, de moniteurs d'enseignement. Nous retrouverons ceci ultérieurement. Précisons que les cours de promotion sociale agricole sont parfois assurés par le système scolaire agricole. 
18.

La majorité des garçons $(88,5 \%)$ a suivi une formation de niveau $V(1)$.Par contre, les filles ont obtenu à peu près aussi souvent un niveau IV $(47 \%)$ qulun niveau $V(53 \%)$.

Niveau de la formation de conversion

\begin{tabular}{|c|c|c|c|c|c|c|c|c|c|c|c|}
\hline & \multicolumn{4}{|c|}{ Niveau $\mathrm{V}$} & \multicolumn{5}{|c|}{ Niveau IV } & \multirow[b]{2}{*}{ 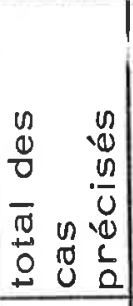 } & \multirow[b]{2}{*}{$\begin{array}{ll} & 0 \\
0 & 0 \\
0 & 0 \\
c & 0 \\
n & 0 \\
0 & 0 \\
0 & 0 \\
0\end{array}$} \\
\hline & 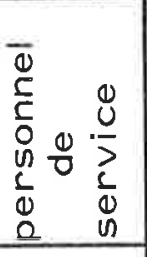 & 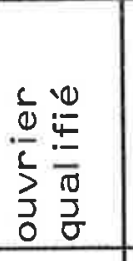 & 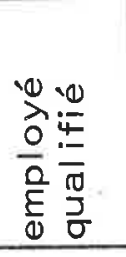 & $\begin{array}{l}\bar{\pi} \\
\stackrel{0}{0} \\
\end{array}$ & 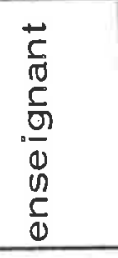 & 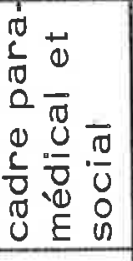 & 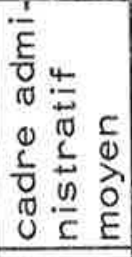 & 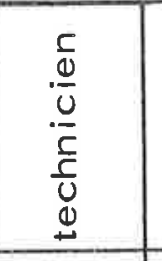 & $\stackrel{\bar{\pi}}{0}$ & & \\
\hline Garçons & \multirow[b]{2}{*}{ - } & \multirow[b]{2}{*}{$\begin{array}{l}558 \\
86,2\end{array}$} & \multirow[b]{2}{*}{$\begin{array}{l}14 \\
2,2\end{array}$} & \multirow[b]{2}{*}{$\begin{array}{l}572 \\
88,4\end{array}$} & \multirow[b]{2}{*}{$\begin{array}{l}3 \\
0,5\end{array}$} & \multirow[b]{2}{*}{$\begin{array}{l}3 \\
0,5\end{array}$} & \multirow[b]{2}{*}{$\begin{array}{l}2 \\
0,3\end{array}$} & \multirow[b]{2}{*}{$(a)_{10,3}^{67}$} & \multirow[b]{2}{*}{$\begin{array}{c}75 \\
11,6\end{array}$} & \multirow[b]{2}{*}{$\begin{array}{l}647 \\
100\end{array}$} & \multirow[b]{2}{*}{2} \\
\hline$\underset{\%}{\operatorname{nombre}}$ & & & & & & & & & & & \\
\hline Filles & & & & & & & & & & & \\
\hline$\underset{\%}{\operatorname{nombre}}$ & $\begin{array}{l}21 \\
12,2\end{array}$ & $\begin{array}{l}8 \\
4,7\end{array}$ & $\begin{array}{c}62 \\
36,0\end{array}$ & $\begin{array}{l}91 \\
52,9\end{array}$ & $\begin{array}{c}26 \\
15,1\end{array}$ & $\begin{array}{c}20 \\
11,6\end{array}$ & $\begin{array}{l}9 \\
5,3\end{array}$ & $(a)_{15,1}^{26}$ & $\begin{array}{l}81 \\
471 \\
\end{array}$ & $\begin{array}{l}172 \\
100 \\
\end{array}$ & 1 \\
\hline
\end{tabular}

(a) y compris 1 cas de Brevet de Technicien Supérieur.

Niveau de la formation de conversion en fonction du niveau de la formation scolaire (cas où la formation scolaire est précisée).

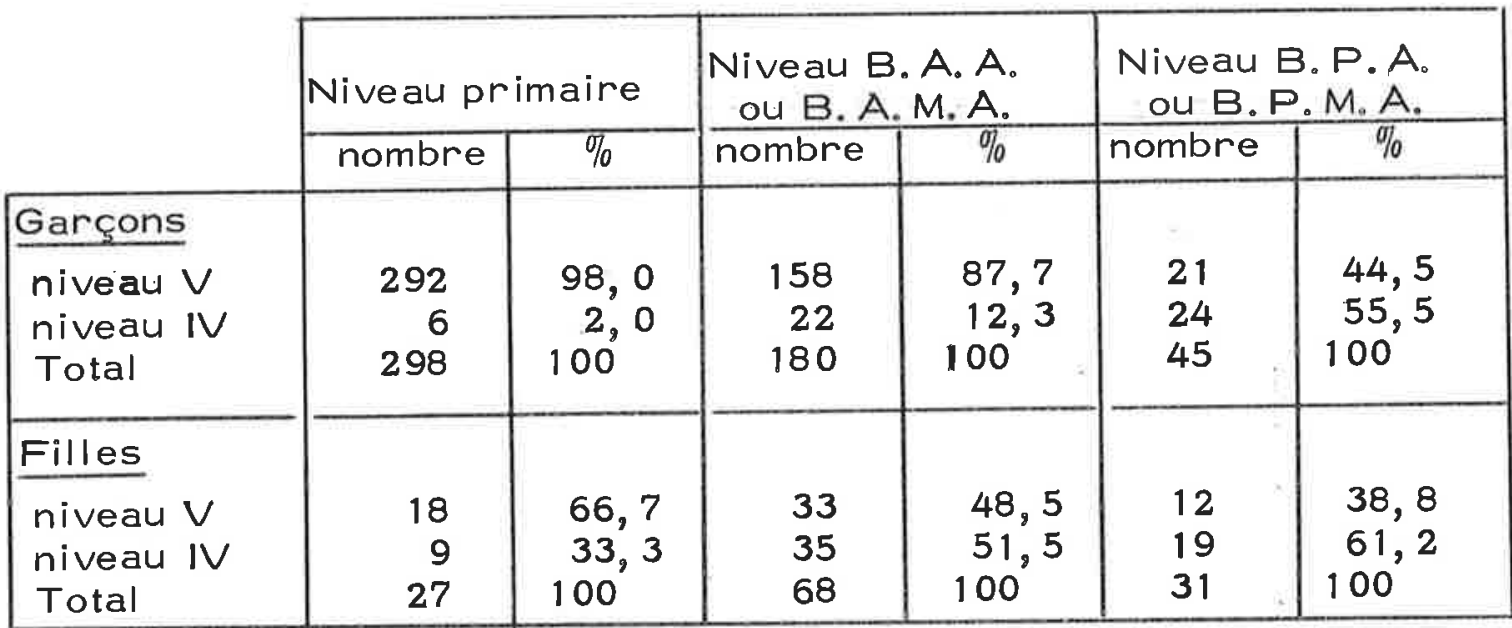

Le niveau de la formation de conversion est-il lié au niveau de la formation scolaire et à l'obtention d'une préformation ?

- La proportion de garçons ayant effectué un stage de niveau IV passe de $2 \%$ chez ceux qui ont un niveauprimaire à $12 \%$ chez les titulaires du B. A. A. et $55,5 \%$ chez les titulaires du B.P.A. 。 Le B. A. A. se différencie peu du niveau primaire et sloppose nettement au B. P. A. . Il n'en est pas de même chez les filles : celles qui ont le $B$. A. A. ou $B$. A. M. A. ont suivi dans plus d'un cas sur deux un stage de niveau IV,

(1) Nous nlavons pas distingué selon qulil y a eu réussite ou échec à l'examen de fin de stage. 
comme celles qui ont le B.P.A. oú B.P.M.A.

- Pour une formation scolaire donnée, la préformation a permis plus souvent aux garçons d'accéder au niveau IV. Mais cette tendance n'est pas constatée chez les filles.

La promotion sociale ici étudiée a pourbut de fournir une qualification non agricole aux jeunes qui n'en avaient pas. Les données précédentes révèlent que dans le cadre de cette action, elle consacre des inégal ités de formation scolaire, tout au moins chez les garçons qui sont plus nombreux que les filles à suivre des études post-scolaires. Par rapport aux titulaires duB. A. A. et surtout du B. P. A. les jeunes de niveau primaire reçoivent proportionnellement moins souvent une formation de conversion, bénéficient moins souvent de la préformation, atteignent moins souvent un niveau IV de qualification. 


\section{III - L'ACCES AUX EMPLOIS NON AGRICOLES}

Les aides du F.A.S.A.S.A. à la conversion visent à éviter qulen sortant de llagriculture, les travailleurs ne connaissent l'infériorité sociale attachée aux emplois de personnels de service et d'ouvriers non qualifiés. D'autre part, le législateur a souhaité une orientationprivilégiée des mutants vers les secteurs para-agricoles, ces secteurs étant considérés comme favorisant plus directement que les autres le développement du secteur proprement agricole.

Ces objectifs et souhaits sont-ils réalisés dans l'exemple de la population étudiée ? II ne nous est pas possible de donner une réponse complète à cette question car les dossiers consultés ne permettent pas de déterminer la position hiérarchique occupée dans le métier exercé. Lors d'une enquête par interviews consacrée à une catégorie particulière de mutants bénéficiaires des aides à la conversion : celle des anciens chefs d'exploitation, il était apparu que tous ces mutants n'accédaient pas à des emplois qualifiés (1). Dans la présente étude, nous ne pouvons indiquer que sommairement la position dans la hiérarchie sociale. Pour faire une bonne analyse de l'utilité économique et sociale, pour les mutants, de la formation post-scolaire reçue, le type d'enquête à réaliser est celui pratiqué par J. GRISEZ dans ses travaux sur la réussite professionnelle des anciens stagiaires de la F. P. A. (2).

Avant d'examiner la catégorie économique et la catégorie sociale des emplois occupés lors dellaccès aux activités non agricoles, notons que les mutants formés en promotion sociale sont généralement restés domiciliés en Ille-et-Vilaine $(88 \%$ des garçons et $82 \%$ des filles). La tendance est identique à celle observée dans l'enquête par sondage. Peu émigrent au loin en début de mutation : à peu près la moitié de ceux et celles qui n'habitent plus I'llle-et-Vilaine résident dans les autres départements limitrophes. Nombreux sont ceux qui cont inuent à avoir leur domicile légal dans leur commune d'origine $(74,5 \%$ des garçons et $33 \%$ des filles). Mais, comme dans l'enquête par sondage, ils travaillent généralement à l'extérieur ( $89 \%$ et $79,5 \%$ des cas).

(1) P. DAUCE et G. JEGOUZO, La mobilité professionnelle des chefs d'exploitation agricole bretons, I. N.R.A. - Station d'Economie Ru rale de Rennes, ronéo, septembre 1969, p. 39.

(2) La réussite professionnelle dans les métiers appris à l'âge adulte, Bulletin du Centre d'Etudes et de Recherches Psychotechniques, juilsept. 1960. 
Localisation du domicile des mutants bénéficiaires de llaide du F.A.S.A.S.A. et de l'ensemble des mutants

\begin{tabular}{|c|c|c|c|c|c|c|c|c|c|}
\hline & \multicolumn{4}{|c|}{ Ille-et-Vilaine } & \multicolumn{2}{|c|}{ Bretagne } & \multirow[b]{2}{*}{$\begin{array}{l}\frac{1}{0} \\
0 \\
0 \\
0 \\
1 \\
0 \\
0 \\
0 \\
\end{array}$} & \multirow[b]{2}{*}{$\begin{array}{ll} & 0 \\
0 \\
0 \\
0 \\
0 \\
0 \\
0 \\
0 \\
0 \\
0 \\
0 \\
0 \\
0 \\
0 \\
0 \\
0 \\
0\end{array}$} & \multirow[b]{2}{*}{$\begin{array}{ll}r & 0 \\
0 & 0 \\
0 & \frac{n}{0} \\
0 & 0 \\
0 & \frac{1}{0} \\
0 & 0\end{array}$} \\
\hline & 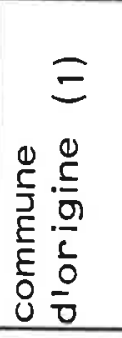 & 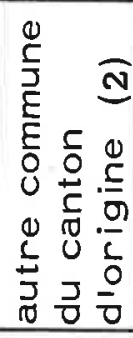 & 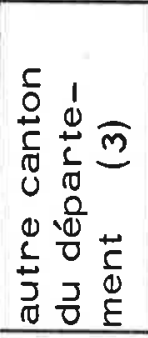 & $\begin{array}{l}\text { త } \\
\bar{\pi} \\
0 \\
\end{array}$ & 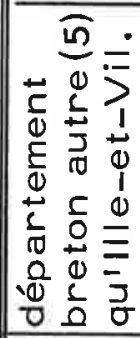 & 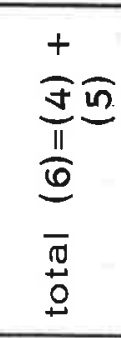 & & & \\
\hline \multirow{2}{*}{$\begin{array}{l}\frac{\text { Garçons }}{\text { - Mutants du }} \\
\text { F. A.S.A.S.A } \\
\text { nombre } \\
\% \\
\text { - Ensemble des } \\
\text { mutants } \\
\text { nombre et } \%\end{array}$} & & & & & & & & & \\
\hline & $\begin{array}{l}406 \\
74,5\end{array}$ & $\begin{array}{l}7 \\
1,3\end{array}$ & $\begin{array}{l}65 \\
11,9\end{array}$ & $\begin{array}{l}478 \\
87,7\end{array}$ & $\begin{array}{l}14 \\
2,6\end{array}$ & $\begin{array}{l}492 \\
90,3\end{array}$ & $\begin{array}{l}53 \\
9,7\end{array}$ & $\begin{array}{l}545 \\
100\end{array}$ & - \\
\hline 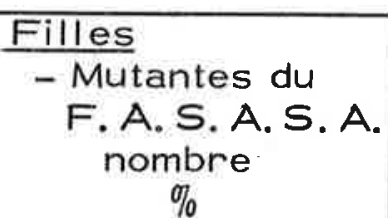 & $\begin{array}{l}39 \\
32,8\end{array}$ & $\begin{array}{l}2 \\
1,7\end{array}$ & $\begin{array}{l}45 \\
37,8\end{array}$ & $\begin{array}{l}86 \\
72,3\end{array}$ & $\begin{array}{l}8 \\
6.7\end{array}$ & $\begin{array}{l}94 \\
79\end{array}$ & $\begin{array}{l}25 \\
21\end{array}$ & $\begin{array}{l}119 \\
100\end{array}$ & 1 \\
\hline $\begin{array}{c}\text { - Ensemble des } \\
\text { mutantes } \\
\text { nombre } \\
\%\end{array}$ & $\begin{array}{l}43 \\
51,9\end{array}$ & $\begin{array}{l}7 \\
8,4\end{array}$ & $\begin{array}{l}23 \\
27,7\end{array}$ & $\begin{array}{l}73 \\
88,0\end{array}$ & $\begin{array}{l}1 \\
1,2\end{array}$ & $\begin{array}{l}74 \\
89,2\end{array}$ & $\begin{array}{c}9 \\
10,8\end{array}$ & $\begin{array}{r}83 \\
100\end{array}$ & 2 \\
\hline
\end{tabular}

La situation d'emploi non agricole que nous présentons est seulement celle de la première profession exercée après la formation de conversion. Dans un certain nombre de cas, l'emploi tenu 6 mois plus tard est connu : le plus souvent le secteur dlactivité nila pas changé; quant à la qualification, elle n'est pas mieux définie que pour l'emploi initial quand il slagit diouvriers.

\section{L'accès aux emplois para-agricoles}

Une minorité de garçons $(14 \%)$ et un peu plus de filles $(29 \%)$ occupent des emplois para-agricoles. Llorientation vers les secteurs para-agricoles était plus fréquente chez les garçons mutants étudiés dans l'enquête statistique (1), la situation étant inverse pour les filles. (1) Comme dans cette enquête, les nomenclatures de catégories d'activité économique retenues pour dél imiter les secteurs para-agricoles sont celles proposées par F. PETIT et A. BRUN dans leur opt ique de définition restreinte (Note sur l'évolution de la population active agricole et para-agricole, I. N.R.A. - Station Centrale d'Economie et de Sociologie Rurales, juin 1967, ronéo). 
22.

Parmi les bénéficiaires des aides du F. A.S. A.S. A., l'accès aux emplois para-agricoles est plus élevéparmi les titulaires diun niveau IV de formation post-scolaire $(69,5 \%$ des garçons et $37,5 \%$ des filles).

Comme les garçons ont surtout effectué des stages préparant aux métiers du bâtiment, ils occupent très souvent un emploi dans ce secteur $(70 \%)$. La F.P.A. ne prépare pas souvent les agriculteurs à exercer les métiers de l'industrie (1). L'orientation vers le bâtiment est plus accentuée que parmi les mutants de l'enquête par sondage $(27 \%)$.

Pour les filles, on relèvedans la population observée au C. N. A.S.E. A. une plus grande proportion d'emplois dans les administrations (catégorie appelée "autres services". dans l'enquête statistique).

L'orientation vers les secteurs para-agricoles chez les mutants qui ont reçu une formation de conversion avec llaide du F.A.S.A.S.A. et chez l'ensemble des mutants

\begin{tabular}{|c|c|c|c|c|}
\hline & \begin{tabular}{|c|} 
Secteurs \\
para-agri- \\
coles
\end{tabular} & $\begin{array}{c}\text { Secteurs } \\
\text { extra-agri- } \\
\text { coles }\end{array}$ & $\begin{array}{c}\text { Total des } \\
\text { cas pré- } \\
\text { cisés }\end{array}$ & $\begin{array}{l}\text { Cas non } \\
\text { précisés }\end{array}$ \\
\hline \begin{tabular}{|l}
$\frac{\text { Garçons }}{\text { Mutants du F.A.S.A. A. }}$ \\
S. A. \\
nombre \\
$\%$ \\
- Ensemble des mutants \\
nombre \\
$\%$
\end{tabular} & $\begin{array}{l}78 \\
14,4 \\
19 \\
19,6\end{array}$ & $\begin{array}{l}463 \\
85,6 \\
78 \\
80,4\end{array}$ & $\begin{array}{r}541 \\
100 \\
\\
97 \\
100\end{array}$ & $\begin{array}{l}4 \\
7\end{array}$ \\
\hline \begin{tabular}{|l|} 
Filles \\
S. Mutantes du F.A.S. A. \\
nombre \\
$\%$ \\
- Ensemble des mutantes \\
nombre \\
$\%$
\end{tabular} & $\begin{array}{l}34 \\
29,1 \\
3 \\
3,6\end{array}$ & $\begin{array}{l}83 \\
70,9 \\
78 \\
96,4 \\
\end{array}$ & $\begin{array}{r}117 \\
100 \\
81 \\
81 \\
100 \\
\end{array}$ & $\begin{array}{l}3 \\
4\end{array}$ \\
\hline
\end{tabular}

\section{Position dans la hiérarchie sociale}

La comparaison des catégories sociales occupées par les mutants étudiés dans l'enquête statistique (2) et par les mutants du C. N. A.S.E. A. est bien sûr à l'avantage des seconds. Alors que $82 \%$ des

(1)En 1967, dans l'ensemble de la France, $54 \%$ des places disponibles dans les centres de F.P.A. I étaient pour des métiers du bâtiment. Source: Statistiques annuelles de I'A.F.P. A. (exercice 1967), p. 91. (2) La plupart n'ont pas obtenu de formation post-scolaire $174 \%$ des garçons et $91 \%$ des filles) et n'ont qu'un niveau C.E.P. ou B. A. A. . 
filles de l'enquête par sondage sont ouvrières et personnels de service, 3 sur 4 des mutantes du F.A.S.A.S. A. sont employées de bureau et cadres moyens. Le F.A.S.A.S.A. permet ainsi aux filles d'échapper aux emplois des services domestiques. Quant aux garçons, ceux étudiés ici sont un peu plus souvent cadres moyens ( $8 \%$ contre $3 \%$ ). Mais la plupart sont ouvriers comme dans l'ensemble des mutants; on ne peut déterminer leurs chances d'ascension dans la hiérarchie ouvrière.

Les catégories sociales sont logiquement liées aux niveaux de formation de conversion. De ce point de vue, l'intérêt de la préformation apparaît bien. $24 \%$ des garçons bénéficiaires dlune préformation sont cadres moyens et 24 filles sur 26 sont cadres moyens ou employées de bureau.

Catégories socio-professionnelles comparées des mutants qui ont reçu une formation de conversion avec llaide du F.A.S.A.S.A. et de l'ensemble des mutants

\begin{tabular}{|c|c|c|c|c|c|c|c|c|}
\hline & 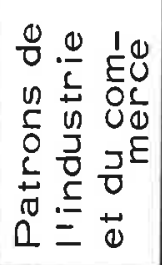 & \begin{tabular}{ll}
$n$ & $n$ \\
0 & $\frac{1}{0}$ \\
\multicolumn{1}{c}{} & $\lambda$ \\
0 & $\lambda$ \\
0 & 0 \\
0 & $\varepsilon$
\end{tabular} & $\frac{\substack{n \\
\frac{U}{2}}}{\frac{0}{0}}$ & $\begin{array}{l}0 \\
\frac{1}{0} \\
\frac{d}{2} \\
2 \\
3 \\
0\end{array}$ & $\begin{array}{lll}\frac{n}{0} & \\
\frac{1}{c} & 0 \\
\frac{0}{0} & 0 \\
0 & 0 & -\frac{1}{2} \\
0 & 0 & \frac{1}{d} \\
\frac{1}{d} & & 0 \\
0 & & n\end{array}$ & 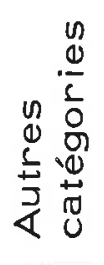 & 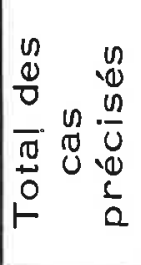 & 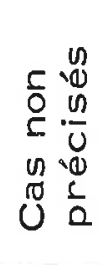 \\
\hline $\begin{array}{l}\text { Garçons } \\
\text { - Mutants du } \\
\text { F.A.S.A.S.A. } \\
\text { nombre } \\
\% \\
\text { - Ensemble des } \\
\text { mutants } \\
\text { nombre } \\
\%\end{array}$ & $\begin{array}{l}2 \\
1,9\end{array}$ & $\begin{array}{c}41 \\
7,6 \\
3 \\
2,9\end{array}$ & $\begin{array}{l}15 \\
2,8 \\
\\
8 \\
7,7\end{array}$ & $\begin{array}{l}483 \\
89,2 \\
\\
90 \\
86,5\end{array}$ & $\begin{array}{l}1 \\
1,0\end{array}$ & $\begin{array}{l}1 \\
0,2\end{array}$ & $\begin{array}{l}104 \\
100\end{array}$ & - \\
\hline $\begin{array}{c}\frac{\text { Filles }}{\text { - Mutantes du }} \\
\text { F.A.S.A.S.A. } \\
\text { nombre } \\
\% \\
\text { - Ensemble des } \\
\text { mutantes } \\
\text { nombre } \\
\%\end{array}$ & $\begin{array}{l}3 \\
3,5\end{array}$ & $\begin{array}{l}39 \\
32,5 \\
1 \\
1,2\end{array}$ & $\begin{array}{l}53 \\
44,2 \\
\\
11 \\
12,9\end{array}$ & $\begin{array}{l}6 \\
5,0 \\
\\
27 \\
31,8\end{array}$ & $\begin{array}{l}2.0 \\
16,7 \\
\\
43 \\
50,6\end{array}$ & $\begin{array}{l}2 \\
1,6\end{array}$ & $\begin{array}{r}120 \\
100 \\
\\
85 \\
100\end{array}$ & - \\
\hline
\end{tabular}

Il faut enfin relever que parmi les 41 garçons et 39 filles qui sont cadres moyens, 16 sont moniteurs et 19 sont monitrices dienseignement agricole. Le système de préformation (14 moniteurs sur 16 ont effectué un stage de préformation) et de promotion sociale, qui se trouve en grande partie al imenté parl'enseignement agricole à temps partiel, a tendance à se perpétuer puisqulil contribue à fournir un personnel enseignant à ce système scolaire. 


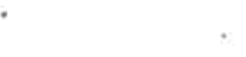




\section{COLLECTION DE LA STATION D'ECONOMIE RURALE DE RENNES}

Série Travaux de Recherches

n०1 - Mars 1965 - D. ASTIER, G. JEGOUZO - Problèmes de compta-

bilité économique régionale : les comptes de llagriculture bretonne.

$n^{\circ} 2-$ Avril 1966

- R. HOVELAQUE - Modèles de structures d'exploitations agricoles.

$n^{\circ} 3$ - Janvier 1968

- J.L. BRANGEON, P: RAINELLI - Les comptes de production et d'exploitation de la branche agricole bretonne. (1960-1966).

$n^{\circ} 4$ - Mars 1968

- G. JEGOUZO - Certaines incidences sur l'agriculture d'une implantation industrielle récente.

n5- Juillet 1968

n6 - Février 1969

- F. BONNIEUX - Méthodes statistiques appliquées à la conduite diun élevage de veaux de boucherie.

- J.L. BRANGEON - Comptabilité conomique régionale et disparités dans le développement et le progrès de l'agriculture française.

$n^{\circ} 7$ - Septembre 1969 - P. DAUCE, G. JEGOUZO - La mobilité professionnelle des chefs d'exploitation agricole bretons. Résultats de deux enquêtes.

$n^{\circ} 8$ - Février 1970 - C. BROUSSOLLE - Les ensembles agro-industriels. n०9 - Janvier 1971 - P. DAUCE, G. JEGOUZO et Y. LAMBERT (avec la collaboration de $B$. ROZE) - La formation des enfants d'agriculteurs et leur orientation hors de l'agricul ture; résultats d'une enquête exploratoire en llle-et-Vilaine.

n॰10 - Février 1971 - F. BONNIEUX - Présentation et applications dlune méthode de simulation.

n॰11 - Février 1971 - D. AUBERT et J.L. BRANGEON - Etude de comptabilité régionale : des comptes de la branche agricole aux ressources du compte d'affectation des ménages agricoles en Bretagne.

Série Etudes et Documents
n¹ - Septembre 1963 - L. MALASSIS - Croissance économique et dévelop- pement rural.
$n^{\circ} 2$ - Mars 1964
- G. JEGOUZO - Essai d'orientation sur la prévision de la population active agricole.
n॰3 - Janvier 1965
régionale.
$n^{\circ} 4$ - Mai 1966
n०5 - Décembre 1966
- J.B. HENRY - L'industrie laitière en Bretagne.
$n^{\circ} 6$ - Avril 1967
- C. BROUSSOLLE - Les industries alimentaires.
- L. MAHE, P. RAINELLI - Contribution à l'étude du coat de la production du porc charcutier.
n०7 - Décembre 1970 - J.L. BRANGEON et P. RAINELLI - Les comptes de patrimoine de l'agriculture : problèmes posés par leur élaboration et essai pour la France entière et la Bre- tagne en 1963 et 1967 .
$n^{\circ} 8-$ Mai 1971 - P. DAUCE, G. JEGOUZO, Y. LAMBERT - La forma- tion des enfants d'agriculteurs et leur orientation d'em- ploi : études complémentaires à une enquête statistique en Ille-et-Vilaine. 
